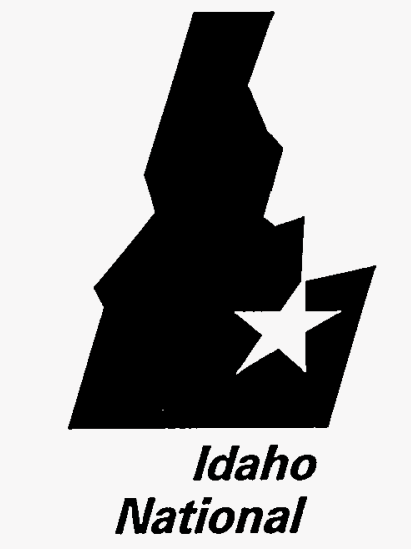

Engineering Laboratory

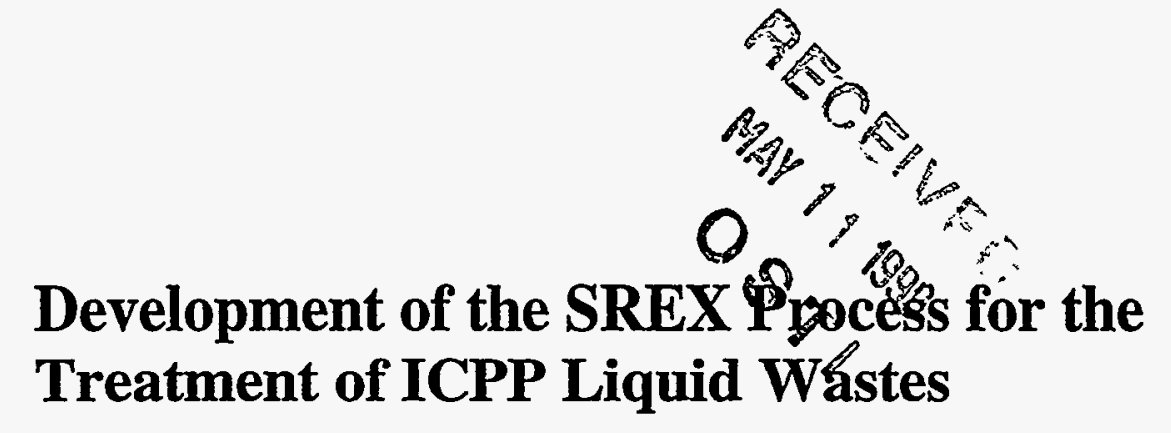

D. J. Wood

J. D. Law

T.G. Garn

R.D. Tillotson

P.A. Tullock

T. A. Todd

LOCKHEED MARTIN 


\section{DISCLAIMER}

This report was prepared as an account of work sponsored by an agency of the United States Government. Neither the United States Government nor any agency thereot, nor any of their employees, makes any warranty, express or implied, or assumes any legal liability or responsibility for the accuracy, completeness, or usefulness of any information, apparatus, product or process disclosed, or represents that its use would not infringe privately owned rights. Relerences herein to any specific commercial product. process, or service by trade name, trademark, manufacturer, or othenwise. does not necessarily constitute or imply its endorsement, recommendation, or favoring by the United States Government or any agency thereof. The views and opinions of authors expressed herein do not necessarily state or reflect those of the United States Government or any agency thereot. 


\section{DISCLAIMER}

Portions of this document may be illegible in electronic image products. Images are produced from the best available original document. 
INEEL/EXT-97-00831

\title{
Development of the SREX Process for the Treatment of ICPP Liquid Wastes
}

\author{
D. J. Wood \\ J.D. Law \\ T.G. Garn \\ R.D. Tillotson \\ P.A. Tullock \\ T.A. Todd
}

Published December 1997

\section{Idaho National Engineering and Environmental Laboratory \\ High Level Waste Program \\ Lockheed Martin Idaho Technologies Company \\ Idaho Falls, Idaho 83415}

Prepared for the

U.S. Department of Energy

Assistant Secretary for

Environmental Management

Under DOE Idaho Operations Office

Contract DE-AC07-941D13223 



\begin{abstract}
The removal of ${ }^{90} \mathrm{Sr}$ from actual and simulated wastes at the Idaho Chemical Processing Plant (ICPP) at the Idaho National Engineering and Environmental Laboratory (INEEL) has been demonstrated with the SREX process. This solvent extraction process employs the extractant $4^{\prime}, 4^{\prime}\left(5^{\prime}\right)$ di-(tbutylcyclohexano)-18-crown-6 in 1-octanol or a mixture of tributyl phosphate and a hydrocarbon diluent called Isopar $L^{\circledR}$. This development work is based upon earlier work performed by Horwitz, et al. at Argonne National Laboratory. Process flowsheets have been designed for testing in countercurrent experiments with centrifugal contactors. The flowsheets have been designed using batch contact solvent extraction methods. The extraction of Sr as well as other interfering ions has been studied. The effect of various parameters including nitric acid dependence, extractant concentration dependence, Hydronium ion concentration, and interferent concentrations upon the extraction efficiency of the process has been evaluated. The radiolysis of the SREX solvent has also been investigated as a function of absorbed gamma radiation. The extraction efficiency of the solvent has been shown to be only slightly dependent upon absorbed dose in the range $0-1000 \mathrm{kGy}$.

The decontamination of actual sodium-bearing waste and dissolved calcine solutions has been accomplished in batch contact flowsheets. Decontamination factors as high as $10 \mathrm{E} 3$ have been obtained with sequential batch contacts. Flowsheets have been developed to accomplish decontamination of the liquid wastes with respect to ${ }^{90} \mathrm{Sr}$ as well as the removal of $\mathrm{Pb}$ and $\mathrm{Hg}$. $\mathrm{Pb}$ may be partitioned from the Sr fraction in a separate stripping procedure using ammonium citrate. This work has led to the formulation of countercurrent flowsheets which have been tested in centrifugal contactors with actual waste and reported in the document INEEL/EXT-97-00832.
\end{abstract}




\section{ACKNOWLEDGMENTS}

This project was supported by the U.S. Department of Energy Office of Environmental Management.

The authors would like to thank Dr. Philip E. Horwitz, Dr. Mark L. Dietz of Argonne National Laboratory for their pioneering work with the SREX process and overall support through many discussions. In addition, we would like to express our appreciation to Mr. George F. Vandegrift, and Dr. Ralph A. Leonard, also of ANL, for design and manufacture of centrifugal contactor equipment and process modeling. Finally, we would like to express our thanks to Dr. Michael Gula of Eichrom Industries, Incorporated for helpful discussion and technical support.

This work was accomplished by a significant integrated effort by Carl Lundholm (remote testing of batch contact flowsheets with actual waste), Troy J. Tranter (radiochemical analysis and consultation), and Jeff Laug (ICP-AES and AAS spectrochemical measurements). The authors are grateful for the efforts put forth by all involved. 


\section{CONTENTS}

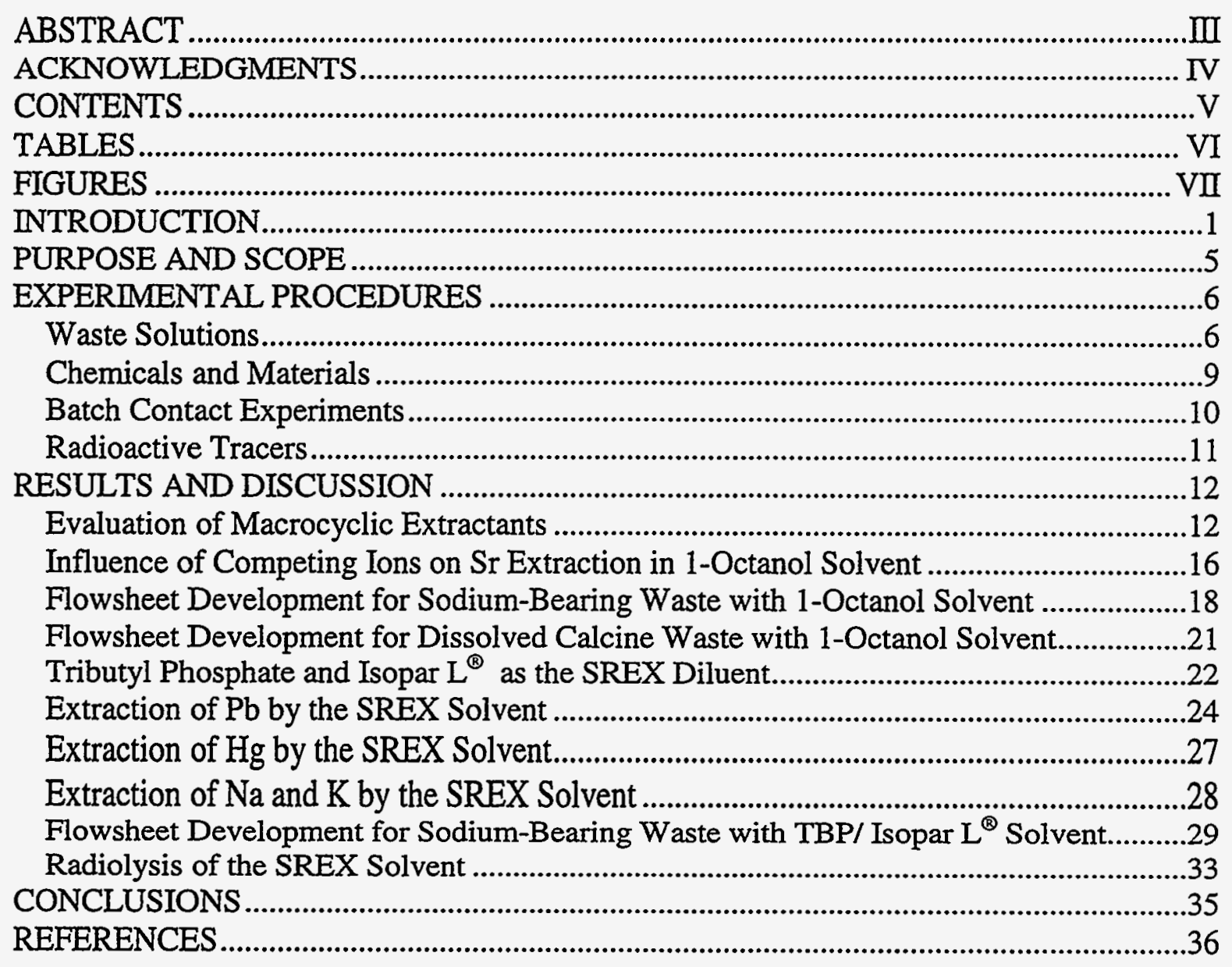




\section{TABLES}

Table 1. Composition of simulated sodium-bearing waste WM-183 and average composition SBW.

Table 2. Composition of actual sodium-bearing waste WM-183 ..................................... 7

Table 3. Composition of simulated dissolved zirconia calcine .................................................. 8

Table 4. Composition of actual zirconia calcine..................................................................8

Table 5. Physical characteristics of Isopar $\mathrm{L}^{\circledR}$ as reported by manufacturer. ........................... 9

Table 6. Radioactive tracers and detection methods........................................................ 11

Table 7. Results from batch contact flowsheet experiments with simulated SBW................ 19

Table 8. Results from batch contact flowsheet experiments with actual WM-185 waste........20

Table 9. Results from sequential batch contacts with actual WM-185 waste......................... 21

Table 10. Results from batch contact flowsheet experiments with actual dissolved zirconia calcine.

Table 11. Percent of total $\mathrm{Sr}$ and $\mathrm{Pb}$ removed from loaded SREX solvent in sequential contacts. .................................................................................................... 26

Table 12. Reagents determined to be ineffective for stripping Hg from loaded SREX

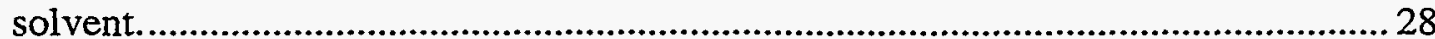

Table 13. Distribution coefficients of $\mathrm{Hg}$ in extraction with various nitric acid solutions........ 28

Table 14. Distribution coefficients for selected metals in batch contact flowsheets with simulated WM-183 waste with the SREX solvent composed of $0.15 \mathrm{M}$ DTBuCH18C6 in $1.5 \mathrm{M}$ TBP/ Isopar $\mathrm{L}^{\circledR}$

Table 15. Extraction of $\mathrm{Sr}$ as a function of total received gamma dose.

Table 16. Distribution coefficient for ${ }^{85} \mathrm{Sr}$ in stripping procedure with irradiated solvent at varying absorbed doses.

Table 17. Extraction of $\mathrm{Sr}$ as a function of nitric acid with irradiated SREX solvent. 34 


\section{FIGURES}

Figure 1. Molecular representations of dicyclohexano-18-crown-6 (left) and 4,4(5), di-(t-butylcyclohexano)-18-crown-6 (DtBuCH18C6). .10

Figure 2. Dependence of $\mathrm{Sr}$ extraction on the initial nitric acid concentration with 1octanol using: $0.15 \mathrm{M}$ DtBuCH18C6 from Manufacturer \#1 ( $)$, DCH18C6 from Aldrich Chemical Company ( $\mathbf{\Delta}), \mathrm{DtBuCH} 18 \mathrm{C} 6$ from Manufacturer \#2 (ם). Aqueous phase: nitric acid in distilled water. .13

Figure 3. Dependence of Sr extraction on the extractant concentration simulated sodium-bearing waste in 1-octanol using: DtBuCH18C6 from Manufacturer \#1 ( $\downarrow)$, DCH18C6 from Aldrich Chemical Company ( $\mathbf{A})$, $\mathrm{DtBuCH} 18 \mathrm{C} 6$ from Manufacturer \#2 (耳). Aqueous phase: simulated sodium-bearing.waste spiked with ${ }^{90} \mathrm{Sr}$.

Figure 4. Dependence of Sr extraction on the extractant concentration from dissolved run \#20 calcine waste in 1-octanol using: DtBuCH18C6 from Manufacturer \#1 ( $\downarrow)$, DCH18C6 from Aldrich Chemical Company (A), $\mathrm{DtBuCH} 18 \mathrm{C} 6$ from Manufacturer \#2 (耳). Aqueous phase: dissolved run \#20 calcine spiked with ${ }^{90} \mathrm{Sr}$.

Figure 5. Total organic carbon present in aqueous phase as a function of nitric acid concentration. Organic phase: 1 -octanol containing $0.15 \underline{\mathrm{M}} \mathrm{DtBuCH} 18 \mathrm{C} 6$ from Manufacturer \#1 ( $\bullet$, DCH18C6 from Aldrich Chemical Company

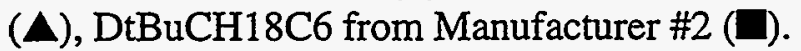

Figure 6. Logarithmic dependence of Sr extraction on the extractant concentration from simulated sodium-bearing waste in 1-octanol using: $\mathrm{DtBuCH} 18 \mathrm{C} 6$ from Manufacturer \#1 ( $\downarrow$ ), DCH18C6 from Aldrich Chemical Company (A), DtBuCH18C6 from Manufacturer \#2 (更).

Figure 7. Dependence of Sr extraction on nitric acid concentration with $0.15 \underline{\mathrm{M}}$ DtBuCH18C6 in 1-octanol from solutions of $0 \underline{\mathrm{M} \mathrm{NaNO}}_{3}(\bullet), 1 \underline{\mathrm{M}}$ $\mathrm{NaNO}_{3}(\boldsymbol{\square}), 2 \mathrm{M} \mathrm{NaNO}_{3}(\boldsymbol{\Delta})$, and $3 \underline{\mathrm{M} N a N O} \mathrm{Na}_{3}(\bullet)$.

Figure 8. Dependence of $\mathrm{Sr}$ extraction from $3 \underline{\mathrm{M}}$ nitric acid on the initial concentration of $\mathrm{LiNO}_{3}(\boldsymbol{\square})$, and NaNO3 $(\bullet)$ by $0.15 \underline{\mathrm{M}} \mathrm{DtBuCH} 18 \mathrm{C} 6$ in 1-octanol.

Figure 9. Dependence of $\mathrm{Sr}$ extraction on the concentration of $\mathrm{Li}(\mathbf{\Lambda}), \mathrm{ZrO}(\mathrm{O}), \mathrm{Ca}$ $(\diamond), \mathrm{Na}(\square)$, and $\mathrm{K}(\square)$ nitrates.

Figure 10. Batch contact flowsheet for simulated SBW. Solid arrows: aqueous phase. Dashed arrows: organic phase. Organic phase: $0.15 \underline{\mathrm{M}}$ DtBuCH18C6 in 1-octanol.

Figure 11. Batch contact flowsheet for actual WM-185 waste. Solid arrows: aqueous phase. Dashed arrows: organic phase. Organic phase: $0.15 \underline{\mathrm{M}}$ $\mathrm{DtBuCH} 18 \mathrm{C} 6$ in 1-octanol.

Figure 12. Batch contact flowsheet for actual dissolved zirconia calcine. Solid arrows: aqueous phase. Dashed arrows: organic phase. Organic phase: $0.15 \mathrm{M} \mathrm{DtBuCH} 18 \mathrm{C} 6$ in 1-octanol.

Figure 13. Dependence of Sr extraction on nitric acid using $0.15 \mathrm{M} \mathrm{DtBuCH} 18 \mathrm{C} 6$ (Manufacturer \#1) in (\$) 1-octanol and (I) $1.2 \mathrm{M} \mathrm{TBP/} \mathrm{Isopar} \mathrm{L}^{\circledR}$. 
Figure 14. Equilibrium organic phase nitric acid concentration on aqueous phase nitric acid in (\$) 1-octanol and (I) $1.2 \mathrm{M}$ TBP/ Isopar $\mathrm{L}^{\circledR}$.

Figure 15. Dependence of $\mathrm{Pb}(\bullet)$ and $\mathrm{Sr}(\mathbf{I})$ extraction on nitric acid with $0.15 \mathrm{M}$ DtBuCH18C6 in 1.2M TBP/ Isopar $\mathrm{L}^{\circledR}$.

Figure 16. Dependence of $\mathrm{Pb}$ extraction on anion molar fraction. aqueous phase: $0.01 \mathrm{M} \mathrm{Pb}\left(\mathrm{NO}_{3}\right)_{2}$ in a solution of nitric acid and hydrochloric acid with a total anion concentration of $0.95 \mathrm{M}$. Organic phase: $0.15 \mathrm{M} \mathrm{DtBuCH} 18 \mathrm{C} 6$ in 1.2M TBP/ Isopar $\mathrm{L}^{\circledR}$.

Figure 17. Dependence of $\mathrm{Hg}(\diamond)$ and $\mathrm{Sr}(\mathbf{})$ extraction on nitric acid with $0.15 \mathrm{M}$ $\mathrm{DtBuCH} 18 \mathrm{C} 6$ in $1.5 \mathrm{M} \mathrm{TBP} /$ Isopar $^{\circledR}$

Figure 18. Dependence of $\mathrm{K}(\$)$ and $\mathrm{Sr}(\mathbf{I})$ Extraction on hydronium ion concentration. Aqueous phase: $3.5 \mathrm{M}$ nitrate ion with $0.001 \mathrm{M} \mathrm{KNO}_{3}$ or $0.001 \mathrm{M} \mathrm{Sr}\left(\mathrm{NO}_{3}\right)_{2}$, adjusted with $\mathrm{LiNO}_{3}$ and $\mathrm{HNO}_{3}$.

Figure 19. Batch contact flowsheet for simulated SBW. Solid arrows: aqueous phase. Dashed arrows: organic phase. Organic phase: $0.15 \mathrm{M} D t B u C H 18 \mathrm{C} 6$ in $1.5 \mathrm{M}$ TBP/ Isopar $\mathrm{L}^{\circledR}$. Aqueous phase: simulated WM-183 sodiumbearing waste spiked with radioisotopes in trace quantitites.

Figure 20. Dependence of extraction on concentration of extractant DtBuCH18C6 in $1.5 \mathrm{M}$ TBP/ Isopar $\mathrm{L}^{\circledR}$ for $\mathrm{Sr}(\bullet), \operatorname{Am}(\boldsymbol{\square}), \mathrm{Pu}(\boldsymbol{\Delta}), \mathrm{U}(\square)$, and $\mathrm{Tc}(\boldsymbol{\bullet})$ in $3 \mathrm{M}$ nitric acid.

Figure 21. Dependence of extraction on concentration of nitric acid in the aqueous phase at equilibrium for $\mathrm{Sr}(\bullet), \operatorname{Am}(\mathbf{\square}), \operatorname{Pu}(\boldsymbol{\Lambda}), \mathrm{U}(\square)$, and $\mathrm{Tc}(\boldsymbol{\theta})$ in 3 $\mathrm{M}$ nitric acid with $0.15 \mathrm{M}$ DtBuCH18C6 in $1.5 \mathrm{M}$ TBP/ Isopar $\mathrm{L}^{\circledR}$. .32 


\section{Development of the SREX Process for the Treatment of ICPP Liquid Wastes}

\section{INTRODUCTION}

The development of waste treatment processes for the removal of long-lived radionuclides from acidic wastes at the Idaho Chemical Processing Plant (ICPP) at the Idaho National Engineering and Environmental (INEEL) has been underway since 1993. These processes are intended for the remediation of $6,800 \mathrm{~m}^{3}$ of aqueous acidic tank waste and $3,800 \mathrm{~m}^{3}$ of solid calcined wastes which will be dissolved prior to treatment. These development efforts will satisfy the requirements of agreements with the State of Idaho, the United States Navy, and other parties. The issues of these agreements are fully described elsewhere. The implementation of these separations processes are based upon economic factors which have been evaluated by an integrated systems analysis of the waste treatment cycle, from waste retrieval to preparation for final disposition. This evaluation and its significance are discussed thoroughly elsewhere.

The length of the half-lives associated with the radionuclides present in radioactive wastes is the basis for concern to the environment and human health factors. The half-lives of the actinides, $\mathrm{Pu}, \mathrm{U}, \mathrm{Am}$, and $\mathrm{Np}$ range from a few hundred years to several thousands of years. The presence of these long-lived elements in significant concentrations presents a challenge to the management of the radioactive wastes. Present methods for storage are not likely to be effective for the period of time required for the actinides to decay to low activities. Therefore, long-term immobilization of these elements must be accomplished. The current approach in the United States and around the world is to secure these elements in immobilized forms such as vitrified glass. This approach appears effective and is among the best options for the disposal of radioactive wastes at this time.

The half-lives of other radionuclides of concern, however, are much shorter. The half-lives of the fission products, ${ }^{90} \mathrm{Sr}$ and ${ }^{137} \mathrm{Cs}$, are 29 years and 30 years, respectively. In general, it can be stated that ten half-lives of these isotopes (approximately 300 years) is the length of time required for these elements to be reduced to activities which are not of concern. It is likely that current technology could yield an engineered containment for these elements which would provide a secure disposition of these elements without the cost of vitrification and deep geologic disposal. However, the current approach to management of these fission products at the INEEL is based upon the conservative practice of immobilizing these isotopes with the actinides in vitrified glass for permanent geologic disposal.

Regardless of the final fate of the fission products, it is clear that the separation of these long-lived components from the waste residing in the current storage facilities must be accomplished in an efficient and timely manner. Human safety, environmental protection, and cost of treatment must be considered with primary importance in the evaluation of waste treatment options.

The technologies which are currently under development at the INEEL have been selected on the basis of technical and economic factors. The baseline technologies for these processes were identified by a peer review which was performed in 1993. ${ }^{1}$ Recognized 
experts in radionuclide separations were utilized as part this evaluation and were tasked with evaluating and ranking specific individual technologies for radionuclide separations. The report from this evaluation identified areas of research and development which the INEEL should pursue in its effort to develop a comprehensive waste treatment plan. Among the technologies identified by this peer review as having a reasonable probability for success were solvent extraction processes, ion exchange processes, and precipitation processes. The technologies have been evaluated experimentally since 1993. The results of these experiments with simulated and actual radioactive wastes are reported in various publications.

The SREX process (StRontium EXtraction) is currently the baseline technology for the partitioning of radiostrontium from the acidic liquid wastes currently stored at the ICPP. This solvent extraction process has been under evaluation since 1993 for its application to INEEL wastes. This report summarizes the results of this research and development effort to date. Further development work is ongoing and will be reported in subsequent reports.

\section{Historical Development of the SREX Process}

The need for the removal of $\mathrm{Sr}$ from acidic solutions in radioactive waste treatment has stimulated much research in the areas of solvent extraction and ion exchange. The remediation of radioactive wastes usually requires the selective removal of $\mathrm{Sr}$ in the presence of numerous other ions. The concentration of $\mathrm{Sr}$ is generally small $(>0.01 \mathrm{M})$ and may reside in solutions with high concentrations of various other metal ions. Therefore, the quantitative removal of Sr requires that the remediation technology have extraordinarily high selectivity for $\mathrm{Sr}$ over the other metal ions present in solution.

The complexation of macrocyclic polyethers, also called crown ethers, for $\mathrm{Sr}$ in aqueous solutions has been studied extensively. Macrocyclic polyethers are a class of compounds first described by C.J. Pederson in 1967, work for which he subsequently was awarded a Nobel prize. Since that time, the chemical and physical properties of these compounds have been studied for their potential application in chemical separations. The macrocycle referred to as 18-crown-6 is known to exhibit binding constants for $\mathrm{Sr}$ which are large enough to be considered as a potential extractant for Sr. Many methods have been proposed for complexation of $\mathrm{Sr}$ in solution with 18-crown-6 and related derivatives.

An evaluation of various synthetic derivatives of 18 -crown- 6 for their selectivity and efficiency for the removal of $\mathrm{Sr}$ from acid solutions was performed by Philip E. Horwitz et al. in 1990. ${ }^{2}$ Dicyclohexano-18-crown-6 (DCH18C6) an 4,4(5), di-(t-butylcyclohexano)-18crown-6 (DtBuCH18C6) were evaluated in this study to determine their extraction characteristics in various organic diluents. Twenty-one diluents including alcohols, carboxylic acids, ketones and esters were employed to determine the extraction constant for $\mathrm{Sr}\left(\mathrm{K}_{\mathrm{Sr}_{\mathrm{r}}}\right)$ in each case. The values of $\mathrm{K}_{\mathrm{Sr}}$ ranged from approximately 5 for ester diluents to approximately 100 in alcohol diluents. The authors demonstrated a relationship between the value of $\mathrm{K}_{\mathrm{S}_{\mathrm{r}}}$ and the solubility of water in the organic diluent. This study resulted in the selection of n-octanol as the diluent of choice for further development of a crown ether extraction process for waste treatment. The t-butyl derivative (DtBuCH18C6) was identified by this study as the preferred extractant based upon its low solubility in the aqueous phase and the linearity of its $\mathrm{Sr}$ extraction plot. 
The term, SREX (Strontium Extraction), was applied to the use of DtBuCH18C6 in a hydrocarbon-based solvent extraction process in 1991 by Horwitz et al. ${ }^{3}$ This report evaluated the extraction of $\mathrm{Sr}$ from dissolved sludge wastes from the Hanford site. Batch contacts were employed to demonstrate the efficient removal of $\mathrm{Sr}$ from acidic solutions in the presence of other ions as well as the efficient stripping of the loaded solvent with $0.5 \underline{\mathrm{M}}$ nitric acid. This report also emphasized the previous work of Yakshin et al. which identified the cis-syn-cis isomer of DCH18C6 as the most effective isomer of five possible isomers for the complexation of $\mathrm{Sr}^{2+}$.

The Argonne National Laboratory research group published a report in 1995 which described the replacement of the 1-octanol diluent in the SREX Process with a hydrocarbon diluent called Isopar $L^{\circledR}$. ${ }^{5}$ Isopar $L^{\circledR}$ is a tradename of the Exxon Corporation. It is a mixture of branched-chain hydrocarbons with no discrete molecular structure, but being composed primarily of twelve carbon molecular units. The replacement of 1-octanol was in response to the discovery that the it was incompatible with hydrocarbon diluents used in the TRUEX process, thereby complicating sequential processing of radioactive waste with the combination of these processes. The incompatibility arises from the fact that low concentrations of 1-octanol which are carried via the aqueous phase to downstream processes in sequential waste treatment operations reduce the performance of the TRUEX and PUREX processes. The report investigated several hydrocarbon diluents and phase modifiers. Norpar $12^{\circledR}$, Isopar $\mathrm{L}^{\circledR}$, Isopar $\mathrm{M}^{\circledR}$, dodecane, and 1-octanol were compared on the basis of strontium distribution coefficient $\left(D_{\mathrm{Sr}}\right)$. Tributyl phosphate (TBP), diamyl amylphosphonate (DAAP), and Cyanex 923 were all studied for phase modification in each of the diluents. It was reported that, in general, the use of TBP results in the highest values for $\mathrm{D}_{\mathrm{Sr}}$. In addition, the extraction of $\mathrm{U}, \mathrm{Pu}$, and $\mathrm{Am}$ by the SREX process solvent with Isopar $\mathrm{L}^{\circledR}$ and 1.2 $\mathrm{M}$ TBP was measured and reported. This initial investigation indicated that the extraction of these three metals is dependent on TBP concentration and is nearly independent of the presence of DtBuCH18C6 in solution.

The development of the SREX process at Argonne National Laboratories was focused initially on the treatment of dissolved tank sludge wastes at the Hanford site. However, the development program for the dissolution of alkaline sludges at the Hanford site was subsequently discontinued. The SREX process, however, was identified in 1993 by a peer review of applicable technologies to have potential application to INEEL liquid wastes. ${ }^{1}$ A research program began in 1993 to develop the SREX process for the removal of ${ }^{90} \mathrm{Sr}$ from sodium-bearing wastes (SBW) and dissolved calcine wastes at the ICPP.

This program was initiated by evaluating the fundamental factors which were considered to be critical to the success of the implementation of a crown ether extraction process at the INEEL. These factors included identification of an effective polyether extractant, the factors which influenced the economic production of the extractant, the identification of an appropriate solvent composition including diluents and phase modifiers, the radiolytic and hydrolytic degradation of the solvent, the hydrodynamic properties of the solvent, and the efficiency of the process (especially in the presence of high concentrations of $\mathrm{Na}$ and $\mathrm{K}$ ions). ${ }^{6}$ Further development studies proceeded with the use of simulated acidic wastes for the evaluation of process chemistry. ${ }^{7,8}$ Batch contact flowsheets were performed with simulated and actual wastes in order to develop appropriate procedures for countercurrent flowsheets. The information gathered in the batch contact flowsheet design experiments was employed to propose process flowsheets for testing in centrifugal contactor 
equipment. Testing was performed either in a $5.5 \mathrm{~cm}$ centrifugal contactor pilot plant or in a $2 \mathrm{~cm}$ centrifugal contactor pilot plant for testing with actual wastes or radioactive tracer tests. ${ }^{9}$

An iterative development program has proceeded in which information from batch contact tests has provided information for the development of countercurrent flowsheets. In turn, the information obtained in countercurrent flowsheets has been utilized to identify areas for further development in laboratory-scale batch contacts. This process has been used to refine process chemistry and to identify problematic issues which require further development.

This report summarizes the important experimental results of the development program which has been initiated at the INEEL. The process chemistry for the SREX process continues to be refined and will be reported in subsequent publications. 


\section{PURPOSE AND SCOPE}

The purpose of these studies was to provide an effective method for the removal of ${ }^{90} \mathrm{Sr}$ from acidic waste streams at the ICPP via the application of molecular recognition technology (crown ether extraction technology). This study was specifically limited to the evaluation of 18-crown- 6 derivatives for $\mathrm{Sr}$ removal as identified by previous studies performed at Argonne National Laboratories, from which the term, SREX (Strontium Extraction) was derived.

The technology evaluated in this project is based upon liquid/liquid extraction using a hydrocarbon diluent in the organic phase. It is assumed in this work that eventual implementation of this process will utilize centrifugal contactor technology in the design of process equipment. The waste streams which have been evaluated for remediation in this study are limited to the acidic streams located at the ICPP at the INEEL. These streams are sodium bearing wastes (SBW) and dissolved calcines, which are the result of the nitric acid dissolution of solid calcines wastes. 


\section{EXPERIMENTAL PROCEDURES}

\section{Waste Solutions}

The simulated wastes employed in this work have been developed based upon experience which has been derived from many development projects. The complexity of the actual waste matrices has been reproduced as closely as possible in the simulant. The primary chemical components of the actual wastes are present in the simulants, as well as many of the minor constituents. However, the simulated matrix does not account for some minor components.

Sodium-bearing waste simulants have been utilized in two forms for this work. A simulant which was prepared to have an average composition of the various liquid wastes stored at the ICPP as well as a specific simulant which represents the actual waste storage tank designated WM-183 have both been utilized in this study. The compositions of the simulated and actual sodium bearing wastes are presented in Tables 1-2.

Table 1. Composition of simulated sodium-bearing waste WM-183 and Average Composition SBW.

\begin{tabular}{||c|c|c|c|c||c||}
\hline Component & $\begin{array}{c}\text { Average } \\
\text { SBW } \\
\underline{M}\end{array}$ & $\begin{array}{c}\text { WM-183 } \\
\underline{M}\end{array}$ & Component & $\begin{array}{c}\text { Average } \\
\text { SBW } \\
\underline{M}\end{array}$ & $\begin{array}{c}\text { WM-183 } \\
\underline{M}\end{array}$ \\
\hline Acid $\left(\mathrm{H}^{+}\right)$ & 1.35 & 1.26 & $\mathrm{~K}$ & $1.9 \mathrm{E}-1$ & $1.38 \mathrm{E}-01$ \\
\hline $\mathrm{Al}$ & $6.5 \mathrm{E}-1$ & $5.56 \mathrm{E}-01$ & $\mathrm{Mn}$ & $1.4 \mathrm{E}-2$ & $1.42 \mathrm{E}-02$ \\
\hline $\mathrm{B}$ & $1.7 \mathrm{E}-1$ & $1.40 \mathrm{E}-02$ & $\mathrm{Mo}$ & $1.5 \mathrm{E}-3$ & $1.49 \mathrm{E}-03$ \\
\hline $\mathrm{Cd}$ & $2 \mathrm{E}-3$ & $2.05 \mathrm{E}-06$ & $\mathrm{Na}$ & 1.26 & 1.32 \\
\hline $\mathrm{Ca}$ & $3.90 \mathrm{E}-2$ & $9.83 \mathrm{E}-02$ & $\mathrm{NO} 3$ & 4.46 & 4.46 \\
\hline $\mathrm{Ce}$ & $3.88 \mathrm{E}-4$ & $3.63 \mathrm{E}-04$ & $\mathrm{Ni}$ & $2.0 \mathrm{E}-3$ & $1.63 \mathrm{E}-03$ \\
\hline $\mathrm{Cl}$ & - & $3.52 \mathrm{E}-02$ & $\mathrm{~Pb}$ & $1.0 \mathrm{E}-3$ & $9.27 \mathrm{E}-04$ \\
\hline $\mathrm{Cs}$ & $7.4 \mathrm{E}-4$ & $7.52 \mathrm{E}-05$ & $\mathrm{PO} 4$ & - & $<9.18 \mathrm{E}-$ \\
$0 \mathrm{Cr}$ & $6.0 \mathrm{E}-3$ & $5.63 \mathrm{E}-03$ & $\mathrm{Sr}$ & $1.7 \mathrm{E}-4$ & $6.80 \mathrm{E}-03$ \\
\hline $\mathrm{F}$ & - & $9.66 \mathrm{E}-02$ & $\mathrm{SO} 4$ & $3.9 \mathrm{E}-2$ & $3.86 \mathrm{E}-02$ \\
\hline $\mathrm{Fe}$ & $3.1 \mathrm{E}-2$ & $2.40 \mathrm{E}-02$ & $\mathrm{Zr}$ & $1.0 \mathrm{E}-3$ & $8.76 \mathrm{E}-03$ \\
\hline $\mathrm{Hg}$ & $3 \mathrm{E}-3$ & $1.93 \mathrm{E}-03$ & & & \\
\hline \hline
\end{tabular}


Table 2. Composition of actual sodium-bearing waste WM-183.

\begin{tabular}{|c|c|c|c|}
\hline Component & $M$ & Component & $M$ \\
\hline Acid $\left(\mathrm{H}^{+}\right)$ & 1.77 & $\mathrm{Mo}$ & 0.001 \\
\hline $\mathrm{Al}$ & 0.64 & $\mathrm{Na}$ & 0.68 \\
\hline $\mathrm{B}$ & 0.013 & $\mathrm{Ni}$ & 0.005 \\
\hline $\mathrm{Cd}$ & 0.001 & $\mathrm{~Pb}$ & 0.001 \\
\hline $\mathrm{Cr}$ & 0.014 & $\mathrm{Zr}$ & $4.2 \mathrm{E}-4$ \\
\hline $\mathrm{Fe}$ & 0.056 & $\mathrm{Alpha}(\mathrm{nCi} / \mathrm{g})$ & 506 \\
\hline $\mathrm{Hg}$ & 0.002 & ${ }^{241} \mathrm{Am}(\mathrm{nCi} / \mathrm{g})$ & 34.9 \\
\hline $\mathrm{K}$ & 0.094 & ${ }^{238} \mathrm{Pu}(\mathrm{nCi} / \mathrm{g})$ & 334 \\
\hline $\mathrm{Mn}$ & 0.013 & ${ }^{239} \mathrm{Pu}(\mathrm{nCi} / \mathrm{g})$ & 123 \\
\hline $\mathrm{Hg}$ & 0.002 & ${ }^{137} \mathrm{Cs}\left(\mathrm{Ci} / \mathrm{m}^{3}\right)$ & 219 \\
\hline $\mathrm{K}$ & 0.094 & ${ }^{90} \mathrm{Sr}\left(\mathrm{Ci} / \mathrm{m}^{3}\right)$ & 201 \\
\hline $\mathrm{Mn}$ & 0.013 & \multicolumn{2}{|c|}{} \\
\hline
\end{tabular}

The development of the SREX process for the treatment of dissolved calcined wastes has employed the dissolved product of non-radioactive calcination operations. This product is representative of the actual radioactive ziroconia calcine which is stored at the ICPP. The compositions of the calcine waste solutions are presented in Tables 3-4. 
Table 3. Composition of simulated dissolved zirconia calcine.

\begin{tabular}{|c|c|c|c||}
\hline Component & $\mathrm{M}$ & Component & $\mathrm{M}$ \\
\hline Acid $\left(\mathrm{H}^{+}\right)$ & 3.51 & $\mathrm{~K}$ & $5.88 \mathrm{E}-04$ \\
\hline $\mathrm{Al}$ & $4.26 \mathrm{E}-01$ & $\mathrm{Mo}$ & $1.78 \mathrm{E}-04$ \\
\hline $\mathrm{B}$ & $6.65 \mathrm{E}-02$ & $\mathrm{Na}$ & $9.13 \mathrm{E}-03$ \\
\hline $\mathrm{Ca}$ & $6.51 \mathrm{E}-01$ & $\mathrm{NO}_{3}$ & 6.04 \\
\hline $\mathrm{Ce}$ & $3.88 \mathrm{E}-04$ & $\mathrm{Ni}$ & $1.75 \mathrm{E}-03$ \\
\hline $\mathrm{Cl}$ & $<8.80 \mathrm{E}-02$ & $\mathrm{~Pb}$ & $<1.93 \mathrm{E}-06$ \\
\hline $\mathrm{Cs}$ & $4.67 \mathrm{E}-03$ & $\mathrm{Sr}$ & $8.39 \mathrm{E}-03$ \\
\hline $\mathrm{Cr}$ & $5.75 \mathrm{E}-03$ & $\mathrm{SO}$ & 0.050 \\
\hline $\mathrm{F}$ & $8.95 \mathrm{E}-01$ & $\mathrm{Zr}$ & $2.13 \mathrm{E}-01$ \\
\hline $\mathrm{Fe}$ & $1.31 \mathrm{E}-02$ & $\mathrm{Nd}$ & $4.07 \mathrm{E}-03$ \\
\hline
\end{tabular}

Table 4. Composition of actual zirconia calcine.

\begin{tabular}{|c|c|c|c|}
\hline Component & $\underline{\mathrm{M}}$ & Component & $\underline{\mathrm{M}}$ \\
\hline Acid $\left(\mathrm{H}^{+}\right)$ & 2.97 & $\mathrm{~K}$ & 0.01 \\
\hline $\mathrm{Al}$ & 0.322 & $\mathrm{Na}$ & 0.08 \\
\hline $\mathrm{B}$ & 0.08 & $\mathrm{NO}_{3}$ & 4.91 \\
\hline $\mathrm{Ca}$ & 0.65 & $\mathrm{Sr}$ & $1.83 \mathrm{E}-5$ \\
\hline $\mathrm{Cs}$ & $2.16 \mathrm{E}-5$ & $\mathrm{SO}_{4}$ & 0.003 \\
\hline $\mathrm{F}$ & 1.02 & $\mathrm{Zr}$ & 0.156 \\
\hline $\mathrm{Fe}$ & $3.27 \mathrm{E}-3$ & & \\
\hline
\end{tabular}




\section{Chemicals and Materials}

All chemicals used in this work were obtained from commercial manufacturers in reagent or analytical grade when possible. All common chemicals such as metal nitrates, nitric acid, sodium carbonate, 1-octanol, tributyl phosphate, and ammonium citrate were prepared from commercially manufactured reagents. All radioisotopes employed in this study were obtained from Isotope Products Laboratories (Burbank, CA) as nominal solutions in nitric or hydrochloric acids.

The polyether extractants used in this study were obtained from various manufacturers. The unsubstituted compound, dicyclohexano-18-crown- 6 was obtained from Aldrich Chemical Company. The substituted compound, 4,4(5), di-(tbutylcyclohexano)-18-crown-6, was obtained from three separate manufacturers: Manufacturer \#1 (Darien, Ill), and Manufacturer \#2 (Orem, Utah). The details of the evaluation and selection of these materials are included in the Results and Discussion section of this report. Figure 1 displays the molecular representation of each of the macrocyclic compounds used in this study.

The hydrocarbon, Isopar $\mathrm{L}^{\circledR}$, was obtained from the Exxon Chemical Corporation. It is available under its trade name and may be purchased from Exxon directly. The chemical is a mixture of branched-chain hydrocarbons which possess and average of twelve carbons in the hydrocarbon structure. This solvent is reported by the manufacturer to have the physical characteristics listed in Table 5 .

Table 5. Physical characteristics of Isopar $\mathrm{L}^{\circledR}$ as reported by manufacturer.

\begin{tabular}{lc}
\hline \multicolumn{1}{c}{ Physical Characteristic } & Value \\
\hline Boiling Point & $189^{\circ} \mathrm{C}$ \\
Flash Point & $64^{\circ} \mathrm{C}$ \\
Aromatic Component Concentration & $40 \mathrm{mg} / \mathrm{L}$ \\
Density & $0.77 \mathrm{~g} / \mathrm{mL}$ \\
Viscosity & $1.38 \mathrm{mPa} . \mathrm{s}$ \\
\hline
\end{tabular}



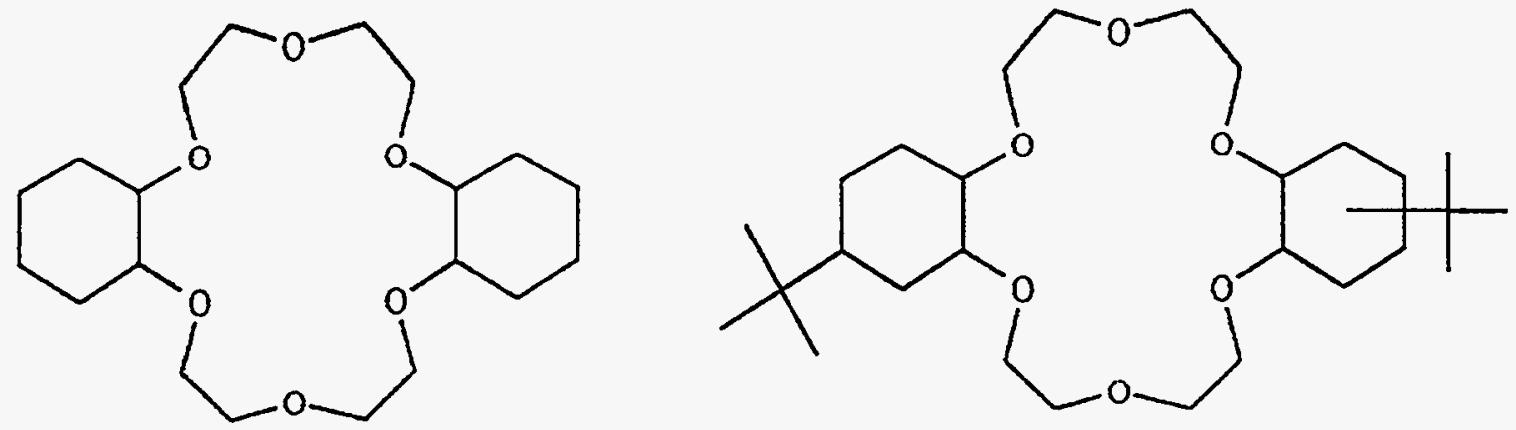

Figure 1. Molecular Representations of dicyclohexano-18-crown-6 (left) and 4,4(5), di-(t-butylcyclohexano)-18-crown-6 (DtBuCH18C6).

\section{Batch Contact Experiments}

Much of the work presented in this report involved the use of laboratory-scale solvent extraction experiments. These experiments were classical solvent extraction experiments, performed using batch methods. The typical method for these experiments utilized small volume (10-50 mL) glass centrifuge tubes to perform the batch contacts. Measured volumes of the appropriate organic phase and aqueous phase were dispensed into the centrifuge tubes with an automatic motorized pipette (Rainin, Inc.). The two phases were then mixed on a vortex-motion mixer for sixty seconds, unless noted otherwise. Separation of the resulting emulsion was accomplished by centrifugation at $5000 \mathrm{rpm}$ for 1 minute. The phases were removed from the test tubes by glass Pasteur pipettes and measured aliquots were taken from each phase for analytical measurements.

Experiments which utilized actual waste solutions in batch contacts were performed in a shielded hot cell, in which all operations were performed remotely. Phase mixing was accomplished by wrist-action shaking with a remote manipulator. Phase separation was accomplished by allowing the emulsion to stand in a separatory funnel until both phases appeared clear.

Batch contact flowsheet experiments were performed in a cross-current method. A measured volume of the organic phase was first pre-equilibrated with an appropriate acid solution three times with an organic to aqueous volume ratio (O:A) equal to one. Aqueous solutions were contacted in appropriate volumes with the organic solution sequentially, with each aqueous phases being removed after contact, sampled for analysis, and discarded. The organic phase was sampled only in the case of radiotracer experiments where analytical methods allow direct measurement of the analytes. The organic phases were not sampled in the non-radioactive experiments because standard analytical techniques do not allow direct measurement of the organic matrix. In these cases, distribution measurements were based upon mass balances using only the analytical results for the aqueous phase. 


\section{Radioactive Tracers}

Radioactive tracers with appropriate decay properties were selected for use in this work. The radiotracers were generally purchased from a commercial supplier in small volumes of acid solutions. These solutions were used by direct addition to experimental solutions or used in stock solution preparation. Care was taken to obtain concentrations of the radiotracers which were in the range to provide favorable counting statistics. Table 6 presents the tracers which were employed in this study and the method of detection used in their measurement.

Table 6. Radioactive tracers and detection methods

\begin{tabular}{|c|c|c|}
\hline Isotope & Emission & Method of Detection \\
\hline${ }^{85} \mathrm{Sr}$ & $\begin{array}{ll}\delta & (0.514 \mathrm{MeV})\end{array}$ & Gamma spectrometry (GeLi) \\
\hline${ }^{90} \mathrm{Sr}$ & $\beta(0.546 \mathrm{MeV})$ & Liquid scintillation \\
\hline${ }^{137} \mathrm{Cs}$ & $\delta \quad(0.512 \mathrm{MeV})$ & Gamma spectrometry (GeLi) \\
\hline${ }^{233} \mathrm{U}$ & $\alpha(4.82 \mathrm{MeV})$ & Liquid scintillation \\
\hline${ }^{241} \mathrm{Am}$ & $\alpha \quad(5.49 \mathrm{MeV})$ & Liquid scintillation \\
\hline${ }^{239} \mathrm{Pu}$ & $\alpha \quad(5.16 \mathrm{Mev})$ & Liquid scintillation \\
\hline
\end{tabular}




\section{RESULTS AND DISCUSSION}

\section{Evaluation of Macrocyclic Extractants}

The selection of an extractant for use in a liquid/liquid extraction process for the treatment of radioactive wastes at the ICPP is an important factor for the successful development of the process. The selectivity of the extraction process must be very high in order to provide a large concentration factor for the radionuclides. The co-extraction of non-radioactive metals decreases the achievable concentration factor and may result in increases in final waste volumes. Additionally, the extraction efficiency of the extractant must be high. The implementation of a waste treatment process which utilizes this process must not require an unreasonably large investment in process equipment. An efficient process minimizes process equipment and cost.

The t-butyl substituted compound $\mathrm{DtBuCH} 18 \mathrm{C} 6$ has been previously reported to be effective for treatment of dissolved sludge wastes. However, these wastes have chemical compositions which differ significantly from ICPP waste streams. For example, the Hanford Site sludge wastes contain a high concentration of Ba relative to ICPP wastes, while ICPP wastes contain much larger concentrations of $\mathrm{Na}$ and $\mathrm{K}$. Since all of these metals are known to be extractable by crown ether derivatives, the difference in chemical composition may be expected to affect the performance of the process significantly. Therefore, an initial study of potential extractants was performed to identify an extractant which could be successfully applied to ICPP wastes.

Two general compounds, which are 18-crown- 6 derivatives, were selected for study. DCH18C6 was purchased from Aldrich Chemicals, while DtBuCH18C6 was obtained from two separate sources. The suppliers of $\mathrm{DtBuCH} 18 \mathrm{C} 6$ are commercial suppliers in the United States. The DtBuCH18C6 reagent was obtained from two sources in an effort to study the influence of varying synthetic procedures on the behavior of the extractant. The dependence of $\mathrm{Sr}$ extraction by these compounds on the concentration of the extractant in the organic phase of 1-octanol has been studied. The results from batch extraction experiments with nitric acids and simulated wastes are shown in Figures 2-4. The data presented indicate a significant difference in the extraction plots of the three compounds studied. The extraction efficiency of the $\mathrm{DtBuCH} 18 \mathrm{C} 6$ compounds are significantly higher than that of DCH18C6 in nitric acid solutions.

However, batch contact experiments with waste solutions reveal a reverse in the trend for the three extractants. In the presence of other ions, the DtBuCH18C6 compound manufactured by manufacturer \#2 yields the lowest $\mathrm{Sr}$ distribution coefficients. One possible explanation of this behavior may be a difference in the molecular and isomeric purity of the reagents. This factor influences the selectivity of the compounds for various ions in solution. This possibility has been investigated by the direct measurement of total soluble organic carbon present in nitric acid solutions which have been placed in contact with the solvents containing the macrocycles. The results of this study are shown in Figure 5. It is apparent from the data that there are significant differences in the loss of the extractants to the aqueous phase. The difference in aqueous solubility of the organic solutions is likely due to differences in the molecular structures of the components of the reagents. The relatively low solubility of the DtBuCH18C6 manufactured by manufacturer 
\#1 is expected of such a compound which has lipophilic t-butyl substituents. The larger extractant solubility of the DCH18C6 compound is expected because it does not contain the lipophilic t-butyl substituents. However, the behavior of the DtBuCH18C6 reagent manufactured by manufacturer \#2 is unexpected based upon its reported molecular structure. The increase in total dissolved carbon with this reagent relative to the first DtBuCH18C6 reagent may be the result of different synthetic preparation routes for this compound.

This study indicates that the synthetic procedure used in the preparation of the macrocyclic extractant is likely to affect the performance of the SREX solvent. Based on the above results, the reagent manufactured by manufacturer \#1 has been employed in further development efforts. It should be noted that the utilization of this extractant in waste treatment processes should be preceded by the development of specific performance criteria in order to assure the quality of the extractant. The compound DtBuCH18C6 is currently being manufactured and sold commercially in the United States in kilogram quantities. Verbal communication with U.S. manufacturers indicate that the synthetic procedure is such that low-cost production of the compound in process-scale quantities is feasible. The current cost of the material in research quantities $(<1 \mathrm{Kg})$ is approximately $\$ 30.00$ per gram. All further work discussed in this report employed the extractant from manufacturer \#1.

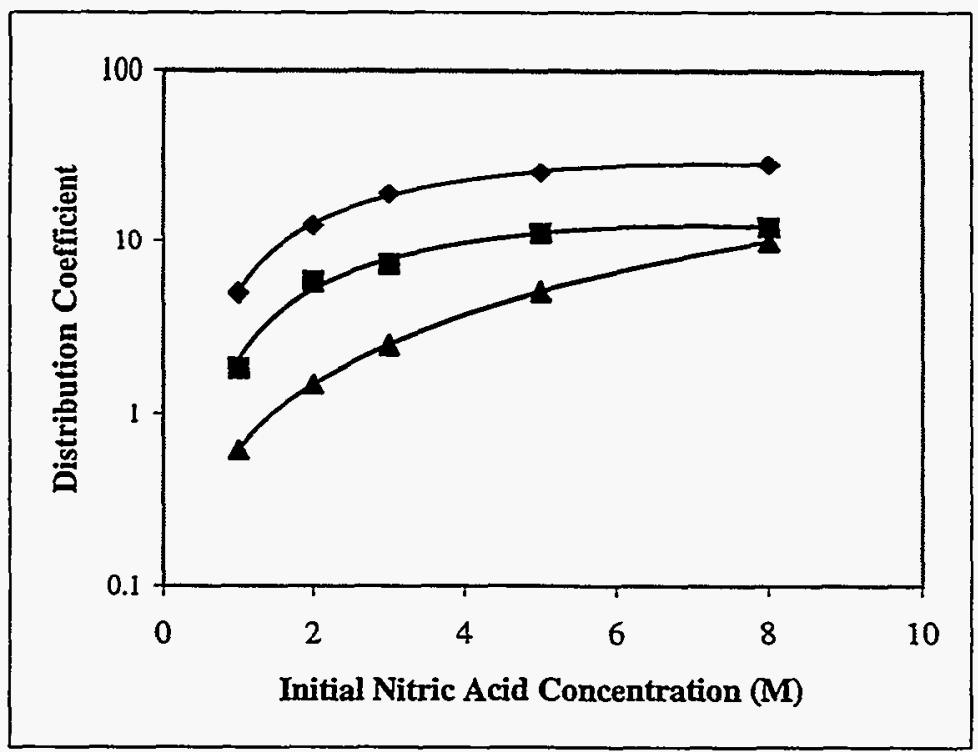

Figure 2. Dependence of Sr extraction on the initial nitric acid concentration with 1octanol using: $0.15 \underline{\mathrm{M}}$ DtBuCH18C6 from Manufacturer \#1 ( $\bullet)$, DCH18C6 from Aldrich Chemical Company ( $\mathbf{A})$, DtBuCH18C6 from Manufacturer \#2 (II). Aqueous phase: nitric acid in distilled water. 


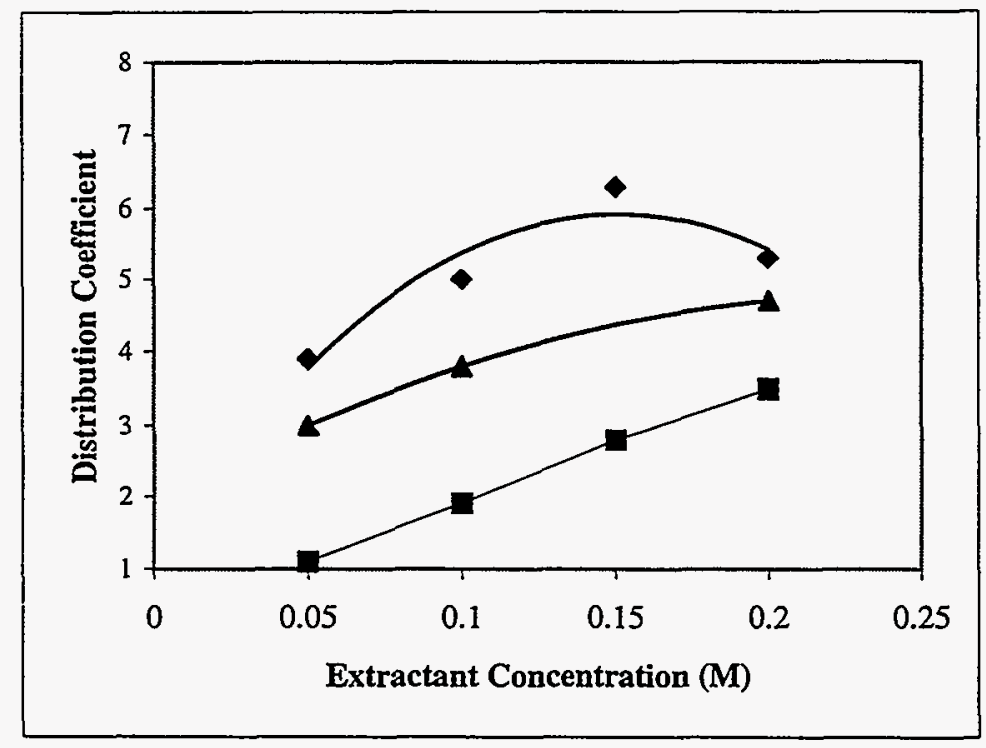

Figure 3. Dependence of Sr extraction on the extractant concentration with simulated sodium-bearing waste in 1-octanol using: DtBuCH18C6 from Manufacturer \#1 ( $)$, DCH18C6 from Aldrich Chemical Company (A), DtBuCH18C6 from Manufacturer \#2 ( $)$. Aqueous phase: simulated sodium-bearing waste spiked with ${ }^{90} \mathrm{Sr}$.

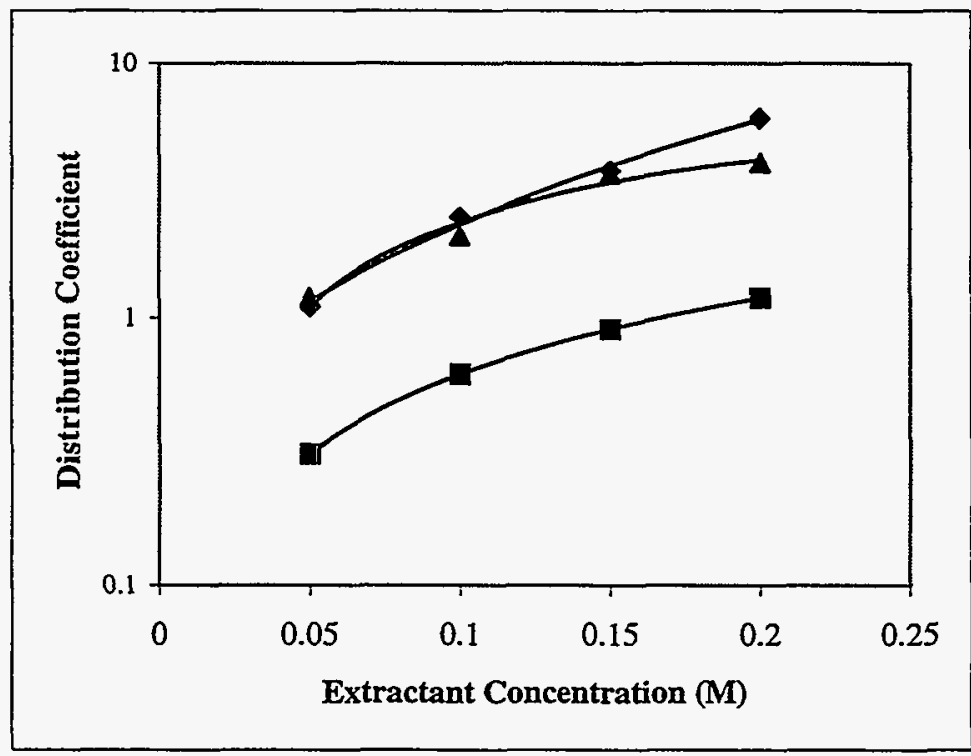

Figure 4. Dependence of Sr extraction on the extractant concentration from dissolved run \#20 calcine waste in 1-octanol using: DtBuCH18C6 from Manufacturer \#1 (४), DCH18C6 from Aldrich Chemical Company (A), DtBuCH18C6 
from Manufacturer \#2 (更). Aqueous phase: dissolved run \#20 calcine spiked with ${ }^{90} \mathrm{Sr}$.

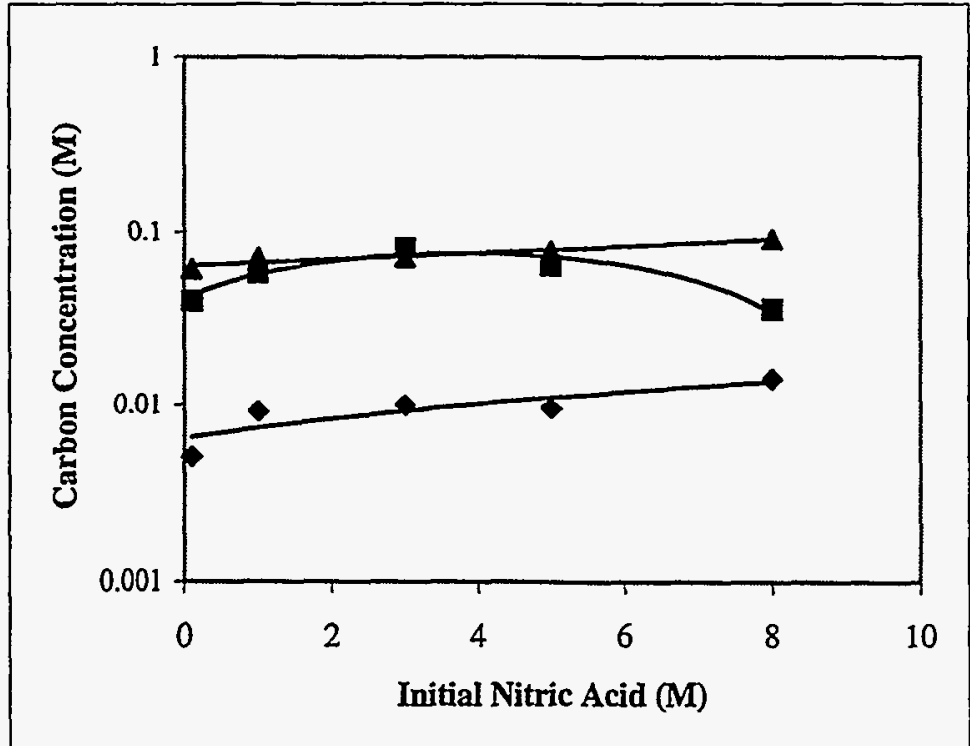

Figure 5. Total organic carbon present in aqueous phase as a function of nitric acid concentration. Organic phase: 1-octanol containing $0.15 \mathrm{M} \mathrm{DtBuCH} 18 \mathrm{C} 6$ from Manufacturer \#1 ( $\downarrow)$, DCH18C6 from Aldrich Chemical Company (A), $\mathrm{DtBuCH} 18 \mathrm{C} 6$ from Manufacturer \#2 (ם).

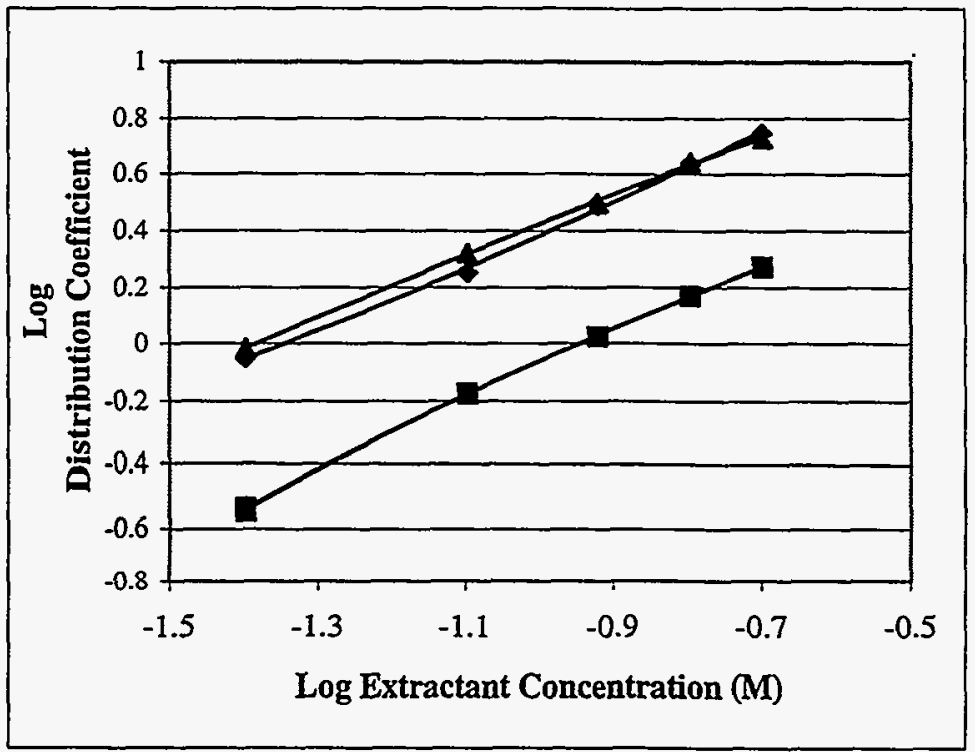

Figure 6. Logarithmic Dependence of Sr extraction on the extractant concentration from simulated sodium-bearing waste in 1-octanol using: DtBuCH18C6 from Manufacturer \#1 ( $\downarrow$ ), DCH18C6 from Aldrich Chemical Company ( $\mathbf{\Delta})$, $\mathrm{DtBuCH} 18 \mathrm{C} 6$ from Manufacturer \#2 (西). 


\section{Influence of Competing Ions on Sr Extraction in 1-Octanol Solvent}

The group I and group II metal ions are known to form solution complexes with macrocyclic polyethers. The presence of these metals in high concentrations in ICPP liquid wastes presents the potential for chemical interferences in the extraction process during waste treatment. The effect of potential chemical interferences on the extraction of $\mathrm{Sr}$ from ICPP wastes has been evaluated using a SREX solvent composition of $0.15 \underline{\mathrm{M}}$ $\mathrm{DtBuCH} 18 \mathrm{C} 6$ in 1-octanol. The results of batch contact experiments with aqueous solutions of varying nitric acid and sodium nitrate concentrations are shown in Figure 7. The figure demonstrates the effect of the interference of $\mathrm{Na}$ upon the extraction of

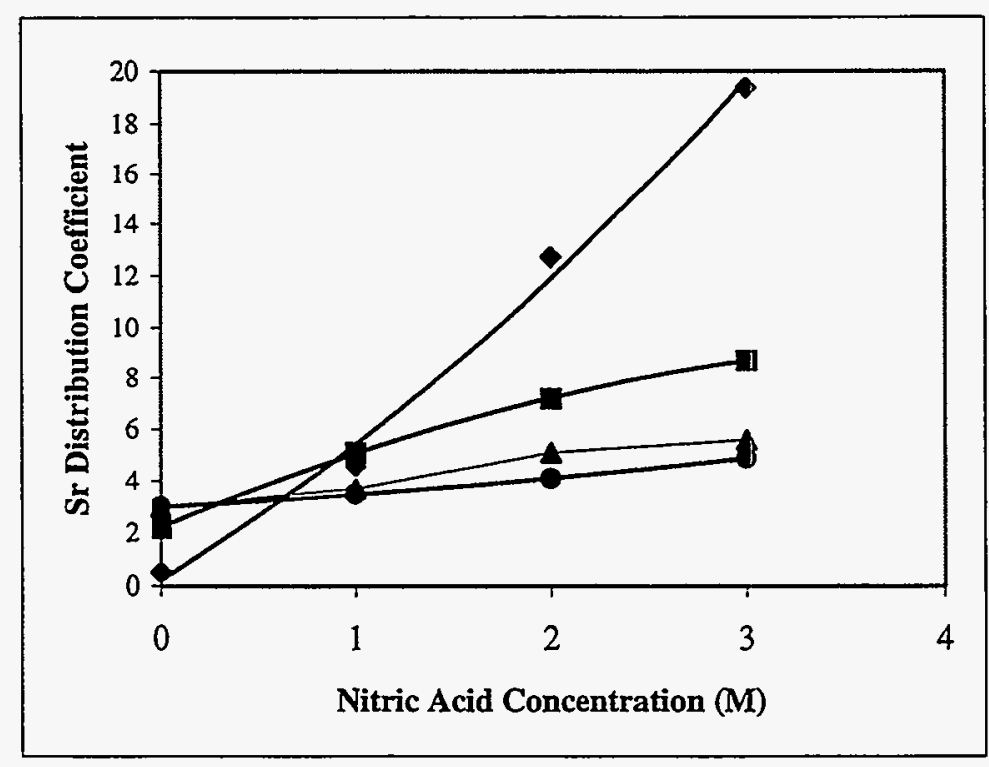

Figure 7. Dependence of Sr extraction on nitric acid concentration with $0.15 \underline{\mathrm{M}}$ DtBuCH18C6 in 1-octanol from solutions of $0 \underline{\mathrm{M} \mathrm{NaNO}} 3(\bullet), 1 \underline{\mathrm{M}} \mathrm{NaNO}_{3}$ $(\boldsymbol{\nabla}), 2 \underline{\mathrm{M} N a N O}{ }_{3}(\boldsymbol{\Delta})$, and $3 \underline{\mathrm{M}} \mathrm{NaNO}_{3}(\bullet)$.

Sr. In solutions which contain no sodium ions, the distribution coefficient may reach a value of approximately 20 in the case of $3 \underline{\mathrm{M}}$ nitric acid. However, as the concentration of $\mathrm{Na}$ is increased, the distribution of $\mathrm{Sr}$ decreases, and $\mathrm{D}_{\mathrm{Sr}}$ is limited to a value of 5 when $3 \mathrm{M}$ $\mathrm{NaNO}_{3}$ is present with $3 \mathrm{M} \mathrm{HNO}_{3}$. This data demonstrates the presence of two factors which influence the extraction of Sr. The first factor is the presence of the $\mathrm{NO}_{3}{ }^{-}$ion. The nitrate ion shifts the equilibrium expression for $\mathrm{Sr}$ in a in a manner which favors extraction. Therefore, the distribution coefficient for $\mathrm{Sr}$ increases as a function of nitrate ion. The second factor, however, acts to counteract the effect of the nitrate ion. The $\mathrm{Na}$ ion is 
extractable by the DtBuCH18C6 macrocycle and competes for available molecules with the $\mathrm{Sr}$ ion. This competition acts to limit the extraction of $\mathrm{Sr}$ when $\mathrm{Na}$ is present.

This point is demonstrated further by the data presented in Figure 8. The data were obtained from batch extractions with the SREX solvent and aqueous phases consisting of 3 $\underline{M}$ nitric acid and varying concentrations of $\mathrm{NaNO}_{3}$ and $\mathrm{LiNO}_{3}$. The presence of $\mathrm{LiNO}_{3}$ has the effect of increasing the measured Sr distribution coefficient. This is the result of the expected behavior of $\mathrm{Li}$, which has a small ionic radius and is not extractable by the SREX solvent. The presence of $\mathrm{NaNO}_{3}$ has the opposite effect on $\mathrm{Sr}$ extraction. The distribution coefficient decreases as a function of $\mathrm{NaNO}_{3}$. The effect of competitive extraction of $\mathrm{Na}$ by the SREX solvent clearly dominates over the effect of the nitrate ion.

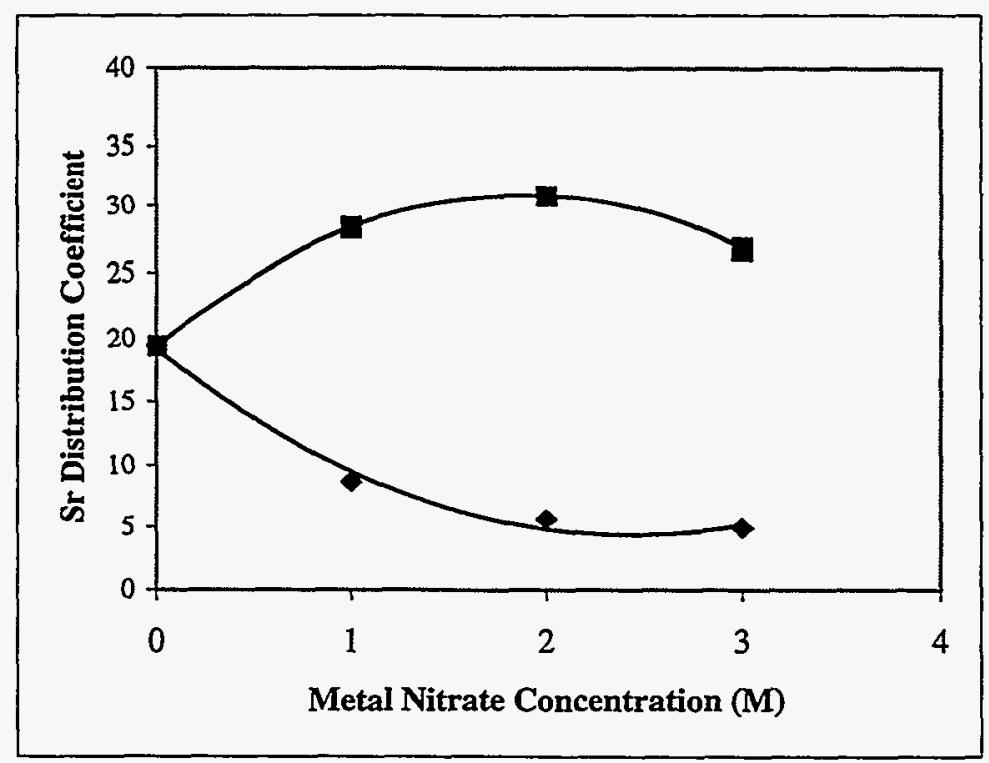

Figure 8. Dependence of $\mathrm{Sr}$ extraction from $3 \underline{\mathrm{M}}$ nitric acid on the initial concentration of $\mathrm{LiNO}_{3}(\mathrm{Q})$, and NaNO3 $(\diamond)$ by $0.15 \mathrm{M} \mathrm{DtBuCH} 18 \mathrm{C} 6$ in 1-octanol.

The effect of the concentration of selected metal nitrates upon the extraction of Sr by the SREX solvent has been studied in order to evaluate the relative effects of these metals. The data from batch contact experiments with $\mathrm{Ca}, \mathrm{Na}, \mathrm{K}, \mathrm{ZrO}$ (zirconyl), and Li nitrates are presented in Figure 9. The data show that these metals interfere according to the order: $\mathrm{K}>\mathrm{Na}>\mathrm{Ca}>\mathrm{ZrO}>\mathrm{Li}$. 


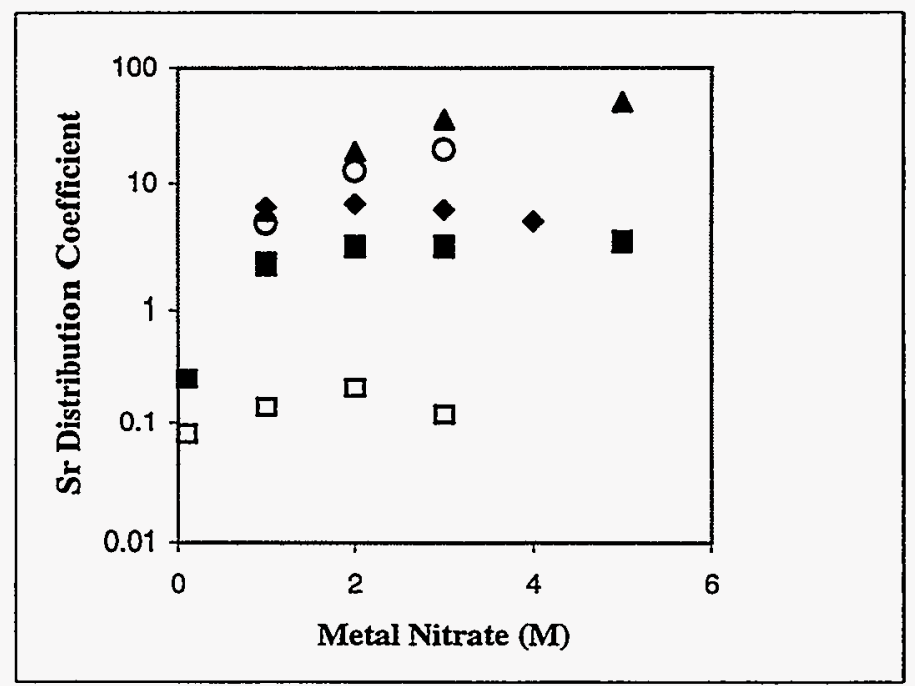

Figure 9. Dependence of $\mathrm{Sr}$ extraction on the concentration of $\mathrm{Li}(\mathbf{\Delta}), \mathrm{ZrO}(0), \mathrm{Ca}$ $(\bullet), \mathrm{Na}(\square)$, and $\mathrm{K}(\square)$ nitrates.

\section{Flowsheet Development for Sodium-Bearing Waste with 1-Octanol Solvent}

The evaluation of the behavior of $\mathrm{Sr}$ in batch contact experiments has been performed in cross-current flowsheets which have been designed to evaluate the chemistry which may be expected to occur in a countercurrent experiment. This work was performed with simulated and actual sodium-bearing waste with a solvent composed of $0.15 \mathrm{M}$ $\mathrm{DtBuCH} 18 \mathrm{C} 6$ in 1-octanol. The batch contact flowsheet was performed according to the diagram in Figure 10. In this experiment, three separate volumes of the SREX solvent were contacted sequentially with a single volume of simulated sodium-bearing waste. The three organic fractions were then combined and this sample was contacted three times sequentially with $3 \underline{\mathrm{M}}$ nitric acid and then three times with $0.01 \mathrm{M}$ nitric acid.

The results of the measurement of ${ }^{85} \mathrm{Sr}$ activities in this experiment are presented in Table 7. The distribution coefficients for $\mathrm{Sr}$ range from 3 to 4 in the extraction contacts. This value, obtained with the simulated solution, is consistent with the previous studies with nitric acid and interfering ions. The waste solution contains high concentrations of $\mathrm{Na}$ and $\mathrm{K}$ ions which limit the extraction of $\mathrm{Sr}$ to a value below what would be expected in a similar solution which contained no $\mathrm{Na}$ and $\mathrm{K}$ ions. The scrub contacts were performed with $3 \underline{\mathrm{M}}$ nitric acid in order to remove extracted metal ions which possess low extraction constants from the organic phase, while retaining the extracted $\mathrm{Sr}$. The distribution coefficients for $\mathrm{Sr}$ are high and appear suitable to provide an effective scrubbing technique. The value for $\mathrm{D}_{\mathrm{Sr}}$ in the first strip contact is approximately 3 . This value decreases rapidly for the second and third contacts. This is a result of the fact that nitric acid which has been extracted by the organic phase during the extraction and scrubbing procedures is present in the first contact. The acid concentration in the organic phase is reduced in each successive contact. The $\mathrm{Sr}$ distribution coefficient in the strip contacts is sufficiently low for very effective removal of Sr from the organic phase. 


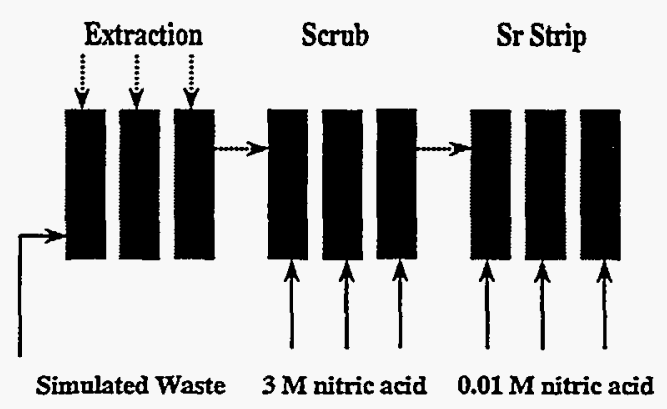

Figure 10. Batch contact flowsheet for simulated SBW. Solid arrows: aqueous phase. Dashed arrows: organic phase. Organic phase: $0.15 \underline{\mathrm{M}} \mathrm{DtBuCH} 18 \mathrm{C} 6$ in 1octanol.

Table 7. Results from Batch Contact Flowsheet Experiments with Simulated SBW.

\begin{tabular}{|l|l|l|l|}
\hline Contact & $\begin{array}{l}\text { 85 Sr Activity } \\
\text { (dps/mL) } \\
\text { Organic Phase }\end{array}$ & $\begin{array}{l}{ }^{85} \text { Sr Activity } \\
\text { (dps/mL) } \\
\text { Aqueous Phase }\end{array}$ & $\begin{array}{l}\text { Distribution } \\
\text { Coefficient } \\
{ }^{85} \text { Sr (D }\end{array}$ \\
\hline Extraction 1 & 351 & 97.2 & 3.61 \\
\hline Extraction 2 & 74.3 & 18.6 & 3.99 \\
\hline Extraction 3 & 14 & 4.21 & 3.33 \\
\hline Scrub 1 & 190 & 14.6 & 13 \\
\hline Scrub 2 & 179 & 10.7 & 16.7 \\
\hline Scrub 3 & 177 & 9.79 & 18.1 \\
\hline Strip 1 & 136 & 44.9 & 3.03 \\
\hline Strip 2 & 16.4 & 121 & 0.14 \\
\hline Strip 3 & 0.38 & 17.6 & 0.02 \\
\hline & & & \\
\hline
\end{tabular}

A similar flowsheet was performed with actual tank waste taken from tank WM-185 at the ICPP. This batch contact flowsheet is diagrammed in Figure 11. The experiment was performed slightly differently from the flowsheet with simulated waste. In the case of the actual waste experiment, a single volume of the organic solution was contacted three times sequentially with the actual waste solution, followed by three contacts with $3 \underline{\mathrm{M}}$ nitric acid, 
and finally by three contacts with $0.01 \underline{\mathrm{M}}$ nitric acid. The results of the experiment are shown in Table 8.

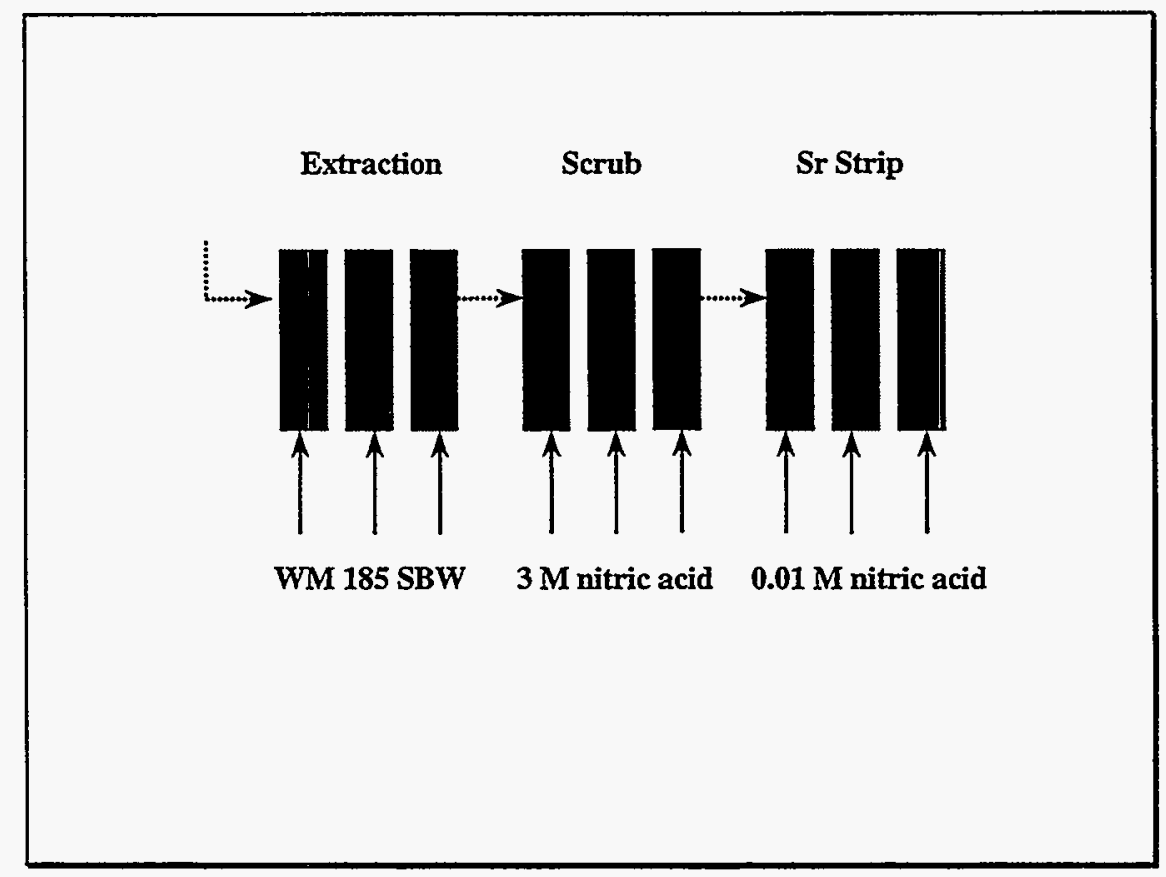

Figure 11. Batch contact flowsheet for actual WM-185 waste. Solid arrows: aqueous phase. Dashed arrows: organic phase. Organic phase: $0.15 \mathrm{MDtBuCH} 18 \mathrm{C} 6$ in 1-octanol

Table 8. Results from Batch Contact Flowsheet Experiments with Actual WM-185 Waste.

\begin{tabular}{|c|c|c|c|}
\hline Contact & $\begin{array}{l}{ }^{90} \mathrm{Sr} \text { Activity } \\
\text { (dps/mL) } \\
\text { Organic Phase }\end{array}$ & $\begin{array}{l}{ }^{90} \mathrm{Sr} \text { Activity } \\
\text { (dps/mL) } \\
\text { Aqueous Phase }\end{array}$ & $\begin{array}{l}\text { Distribution } \\
\text { Coefficient } \\
{ }^{90} \mathrm{Sr}\left(\mathrm{D}_{\mathrm{Sr}}\right)\end{array}$ \\
\hline Extraction 1 & $2.53 \mathrm{E} 6$ & $7.83 \mathrm{E} 5$ & 3.24 \\
\hline Extraction 2 & $4.75 \mathrm{E} 6$ & $1.54 \mathrm{E} 6$ & 3.09 \\
\hline Extraction 3 & 6.71E6 & $2.09 \mathrm{E} 6$ & 3.21 \\
\hline Scrub 1 & 4.79E6 & 5.84E5 & 8.19 \\
\hline Scrub 2 & 4.33E6 & $3.80 \mathrm{E} 5$ & 11.4 \\
\hline Scrub 3 & $4.12 \mathrm{E} 6$ & -------- & $19.6^{*}$ \\
\hline Strip 1 & $3.89 \mathrm{E} 6$ & $1.56 \mathrm{E} 6$ & 2.49 \\
\hline Strip 2 & --.--..- & $3.98 \mathrm{E} 6$ & $0.03^{*}$ \\
\hline Strip 3 & $7.64 \mathrm{E} 3$ & $5.33 \mathrm{E} 5$ & 0.01 \\
\hline
\end{tabular}

These values were obtained by mass balance instead of direct measurement. 
An experiment was performed with actual WM-185 sodium-bearing waste in order to demonstrate the ability of the SREX solvent to achieve desired levels of decontamination. In this experiment, ten mLs of the aqueous waste were contacted with an equal volume of the SREX solvent ( $0.15 \mathrm{M}$ DtBuCH18C6 in 1-octanol). After the phases had settled and separated, the aqueous phase was removed and contacted with another volume of fresh SREX solvent. This procedure was performed six times, so that the same volume of WM185 waste had been contacted sequentially six times with fresh SREX solvent. The initial WM-185 waste solution was sampled as well as the final (sixth) organic and aqueous phases for ${ }^{90} \mathrm{Sr}$. The results are shown in Table 9. The overall decontamination factor obtained in this experiment is in the range which is expected to provide decontamination suitable to yield an NRC class-A low level waste.

Table 9. Results from Sequential Batch Contacts with Actual WM-185 Waste.

\begin{tabular}{|l|l|l|l|}
\hline Sample & ${ }^{90}$ Sr Activity (dps/mL) & Decontamination Factor & $\%$ Removal \\
\hline WM-185 Feed & $4.27 \mathrm{E} 6$ & & \\
\hline $\begin{array}{l}\text { Aqueous (contact } \\
\# 6\end{array}$ & $4.17 \mathrm{E} 2$ & & \\
\hline Organic (contact \#6) & $6.33 \mathrm{E} 4$ & 10240 & $99.99 \%$ \\
\hline
\end{tabular}

\section{Flowsheet Development for Dissolved Calcine Waste with 1-Octanol Solvent}

Based upon the initial results from the flowsheet development with sodium bearing waste, a batch contact flowsheet with actual dissolved zirconia calcine was tested. The batch contact flowsheet was similar to that tested with sodium-bearing waste and is shown in Figure 12. The strip solution is different from the previous development study. It is composed of 0.25 $\underline{M}$ HEDPA in $0.01 \underline{M}$ nitric acid. This solution was selected because it was shown to prevent a precipitate which formed at the interface of the organic and aqueous phases during the stripping contacts when a solution of $0.01 \underline{\mathrm{M}}$ nitric acid was employed. The results of this experiment are shown in Table 10. The distribution coefficients for $\mathrm{Sr}$ in the extraction contacts are significantly higher than those obtained with sodium-bearing waste as described previously. This is due to the fact that the dissolved calcine solution has much lower Na and $\mathrm{K}$ concentrations which present interferences in the sodium-bearing waste flowsheet. This lack of interference combined with a slightly higher nitrate ion concentration results in values for $D_{\mathrm{Sr}}$ which are approximately 20 . The values in the strip contacts indicate that $\mathrm{Sr}$ is stripped efficiently from the loaded solvent. 


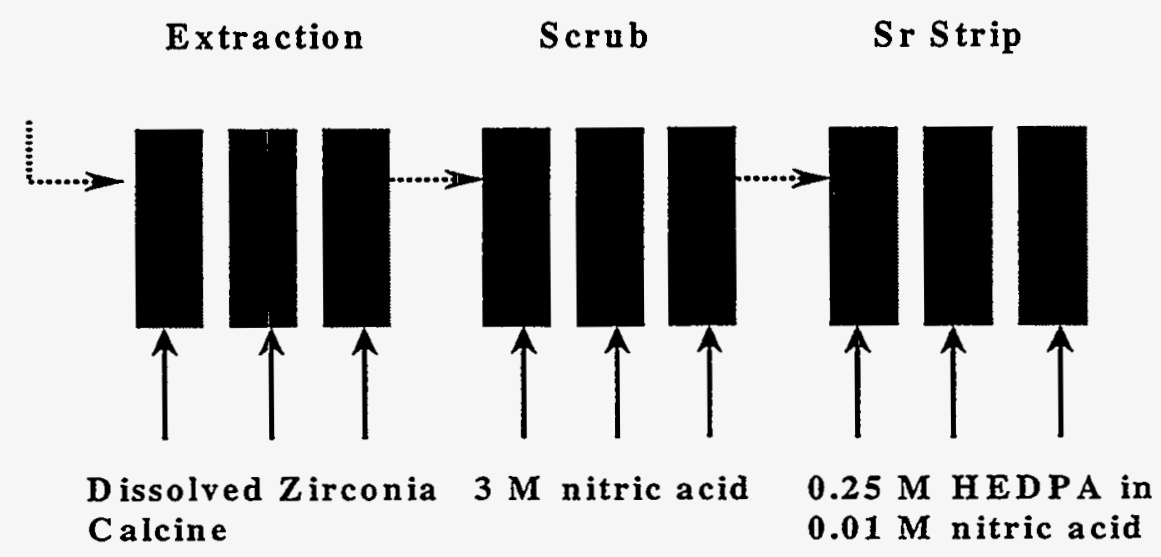

Figure 12. Batch contact flowsheet for actual dissolved zirconia calcine. Solid arrows: aqueous phase. Dashed arrows: organic phase. Organic phase: $0.15 \underline{\mathrm{M}}$ DtBuCH18C6 in 1-octanol.

Table 10. Results from Batch Contact Flowsheet Experiments with Actual Dissolved Zirconia Calcine.

\begin{tabular}{|c|c|c|c|}
\hline Contact & $\begin{array}{l}{ }^{90} \mathrm{Sr} \text { Activity } \\
\text { (dps/mL) } \\
\text { Organic Phase }\end{array}$ & $\begin{array}{l}{ }^{90} \text { Sr Activity } \\
\text { (dps/mL) } \\
\text { Aqueous Phase } \\
\end{array}$ & $\begin{array}{l}\text { Distribution } \\
\text { Coefficient } \\
{ }^{90} \mathrm{Sr}\left(\mathrm{D}_{\mathrm{Sr}}\right) \\
\end{array}$ \\
\hline $\begin{array}{l}\text { Dissolved } \\
\text { Calcine } \\
\end{array}$ & & $5.72 \mathrm{E} 10$ & \\
\hline Extraction 1 & $5.44 \mathrm{E} 10$ & $2.79 \mathrm{E} 9$ & 19.5 \\
\hline Extraction 2 & $1.06 \mathrm{E} 11$ & $5.39 \mathrm{E} 9$ & 19.7 \\
\hline Extraction 3 & $1.56 \mathrm{E} 11$ & $7.38 \mathrm{E} 9$ & 21.1 \\
\hline Scrub 1 & $1.5 \mathrm{E} 11$ & $6.06 \mathrm{E} 9$ & 24.7 \\
\hline Scrub 2 & $1.49 \mathrm{E} 11$ & $7.2 \mathrm{E} 8$ & 207 \\
\hline Scrub 3 & $1.43 \mathrm{E} 11$ & $6.06 \mathrm{E} 9$ & 23.6 \\
\hline Strip 1 & $1.18 \mathrm{E} 11$ & $2.48 \mathrm{E} 10$ & 4.77 \\
\hline Strip 2 & $2.06 \mathrm{E} 10$ & $9.78 \mathrm{E} 10$ & 0.21 \\
\hline Strip 3 & $5.68 \mathrm{E} 9$ & $1.49 \mathrm{E} 10$ & 0.38 \\
\hline
\end{tabular}

\section{Tributyl Phosphate and Isopar $\mathrm{L}^{\star}$ as the SREX Diluent}

The replacement of 1-octanol as the diluent in the SREX process solvent has been investigated. The reason for this effort is that the widespread use of dodecane, kerosene, 
and various other aliphatic hydrocarbon solvents in solvent extraction processes in the past is likely to provide Isopar $\mathrm{L}^{\circledR}$, an aliphatic solvent from the Exxon Corporation, with a favorable reception when implemented on a process basis. 1-octanol, conversely, has not been widely employed in such processes and may be viewed unfavorably for implementation. Alcohols are known to react with nitric acid to form chemically unstable nitrated organic species. This potential may present unacceptable safety hazards in the use of the octanol solvent.

The use of tributyl phosphate (TBP) in the process solvent increases the solubility of organic phase solution complexes and prevents the formation of additional phases within the solvent system as a result of high phase loading. The TRUEX solvent extraction process under development at the INEEL employs a similar solvent system which contains $1.4 \mathrm{M}$ TBP in Isopar $L^{\circledR}$. The TBP in this system also behaves as a phase modifier for the prevention of third phase formation.

Two concentrations of TBP have been investigated in this study. The initial work was performed with $1.2 \mathrm{M}$ TBP based upon the recommendation of previous researchers at the Argonne National Laboratory. This concentration performed well when applied to decontamination of sodium-bearing waste solutions. However, third phase formation in dissolved calcine flowsheets led to an increase of the TBP concentration to $1.5 \mathrm{M}$.

The dependence of $\mathrm{D}_{\mathrm{Sr}}$ upon the initial nitric acid concentration in the aqueous phase using the 1.2 M TBP/ Isopar $\mathrm{L}^{\circledR}$ diluent is compared with the 1-octanol diluent in Figure 13. It is clear from the plot that the 1-octanol diluent provides higher distribution coefficient values than that of the TBP/ Isopar $\mathrm{L}^{\circledR}$ solvent across the entire range of nitric acid concentrations. The lower values are still high enough to be considered reasonable as a basis for a countercurrent extraction process.

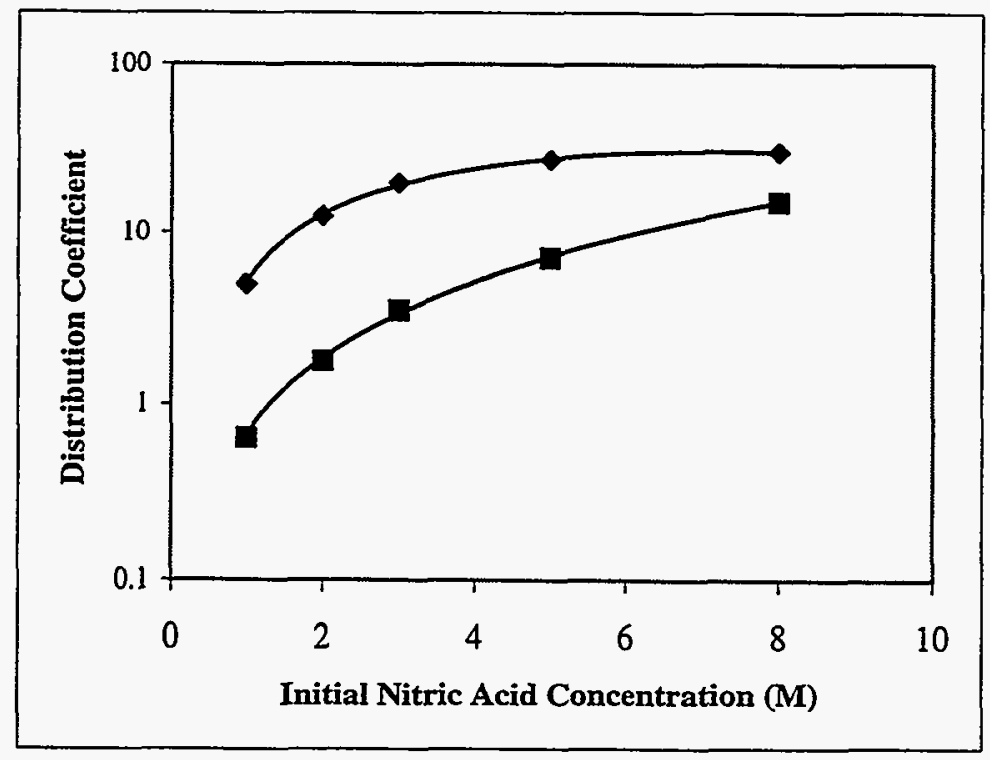

Figure 13. Dependence of Sr Extraction on Nitric Acid using 0.15 M DtBuCH18C6 (Manufacturer \#1) in ( $\diamond$ ) 1-octanol and (I) 1.2 M TBP/ Isopar $L^{\circledR}$. 
The extraction of nitric acid by the octanol and Isopar $L^{\circledR}$ diluents has been studied and determined by acid/base titration of organic and aqueous solutions which have been contacted in equal volume ratios and are in chemical equilibrium. The results of this study are shown in Figure 14. The acid extraction plots of the two solvents are similar. The TBP/ Isopar $\mathrm{L}^{\circledR}$ diluent demonstrates slightly higher distribution coefficient of nitric acid across the range of acids studied, but the difference is not large in magnitude.

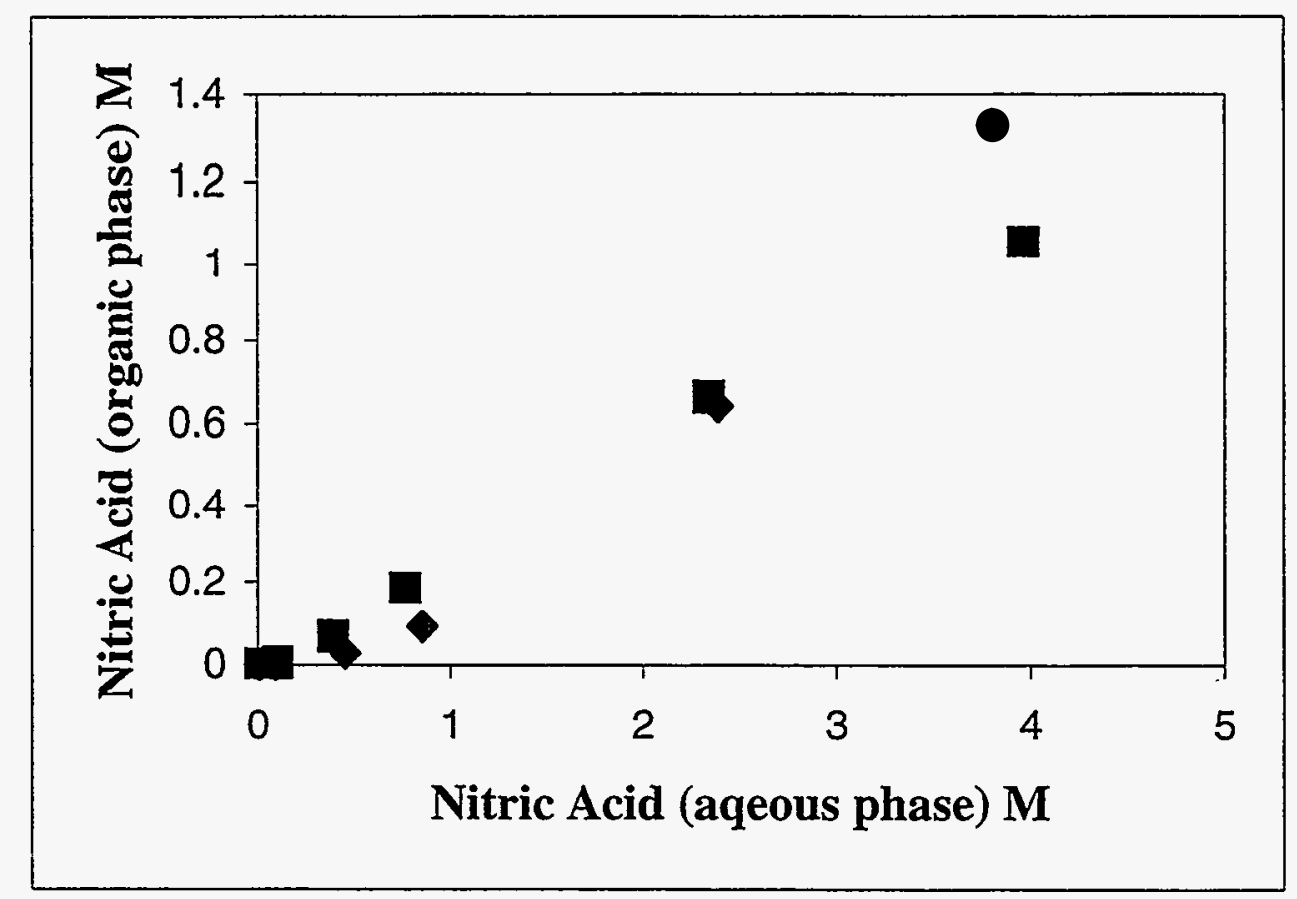

Figure 14. Equilibrium Organic Phase Nitric Acid Concentration on Aqueous Phase Nitric

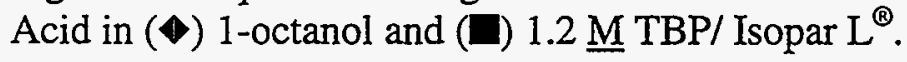

\section{Extraction of $\mathrm{Pb}$ by the SREX Solvent}

The extraction of $\mathrm{Pb}$ by the SREX solvent $(0.15 \mathrm{M}$ DtBuCH18C6 in $1.2 \mathrm{M}$ TBP/ Isopar $\mathrm{L}^{\circledR}$ ) has been studied as a possible interferent in the removal of ${ }^{90} \mathrm{Sr}$ from INEEL waste solutions. The dependence of $\mathrm{Pb}$ extraction on nitric acid is shown and compared with $\mathrm{Sr}$ in Figure 15. The extraction percent for $\mathrm{Pb}$ and $\mathrm{Sr}$ exhibit very different nitric acid dependencies. At a nitric acid concentration of $0.5 \mathrm{M}, \mathrm{Pb}$ is extracted nearly quantitatively. The value for $\mathrm{Sr}$, however, is very low. This indicates that at a nitric acid concentration of $0.5 \mathrm{M}$, Sr may be effectively stripped from the organic phase. $\mathrm{Pb}$, however, will not be stripped at the same concentration. These data suggest that only very low acid concentrations may be successful at removing extracted $\mathrm{Pb}$ from the solvent. 


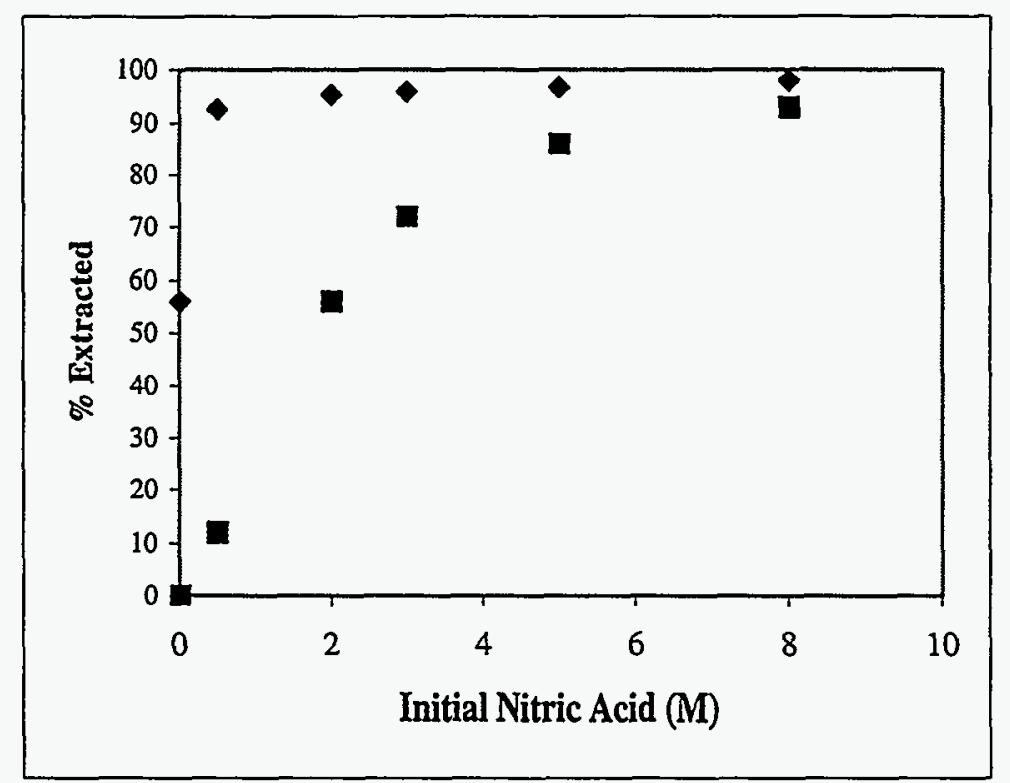

Figure 15. Dependence of $\mathrm{Pb}(\bullet)$ and $\mathrm{Sr}(\mathbf{I})$ Extraction on Nitric Acid with $0.15 \underline{\mathrm{M}}$ $\mathrm{DtBuCH} 18 \mathrm{C} 6$ in $1.2 \mathrm{M} \mathrm{TBP} /$ Isopar $^{\circledR}$.

The stripping of $\mathrm{Pb}$ from the loaded SREX solvent has been investigated in batch contact experiments. It was observed that when a solution of the SREX solvent which had been contacted with solutions of lead nitrate in order to load the solvent was subsequently contacted with $0.5 \underline{\mathrm{M}}$ nitric acid as a stripping solution, a white precipitate formed upon centrifugation at the interface of the organic and aqueous phase. It is believed that this precipitate is a crown:Pb:nitrate complex whose solubility in both liquid phases is very low. This precipitate was subsequently observed in many situations where various concentrations of nitric acid, ranging from zero (water) to $0.5 \mathrm{M}$, were employed as strip reagents.

The presence of the insoluble $\mathrm{Pb}$ precipitate led to the investigation of possible complexants which would be soluble in the aqueous phase and might form solution complexes with $\mathrm{Pb}$ and allow stripping of $\mathrm{Pb}$ from the loaded organic phase without precipitation. An experiment was performed in which $8 \mathrm{mLs}$ of the SREX solvent was contacted one time with $4 \mathrm{mLs}$ of $3 \underline{\mathrm{M}}$ nitric acid containing $0.005 \underline{\mathrm{M}} \mathrm{Pb}\left(\mathrm{NO}_{3}\right)_{2}$ and 0.005 $\underline{\mathrm{M}} \mathrm{Sr}\left(\mathrm{NO}_{3}\right)_{2}$. The solvent was then divided into $2 \mathrm{~mL}$ fractions and contacted three times successively with various potential stripping solutions. Table 11 presents the results of the experiment. The total recovery of $\mathrm{Pb}$ after three contacts with $0.01 \mathrm{M}$ nitric acid is less than fifty percent. The recovery of $\mathrm{Pb}$ with ammonium citrate, HEDPA, and EDTA, however, is much better. This indicates that these reagents increase the aqueous solubility of the $\mathrm{Pb}$ complex which is resident in the loaded organic phase. Ammonium citrate was selected as the stripping reagent for further studies based upon the observation that phosphate from HEDPA is not favorable for eventual waste form compositions and that the use of EDTA has met some resistance based upon its safety characteristics. It is possible, however, that any of these reagents would yield satisfactory stripping results. 
Table 11. Percent of Total $\mathrm{Sr}$ and $\mathrm{Pb}$ Removed from Loaded SREX Solvent in Sequential Contacts.

\begin{tabular}{|l|l|l|l|l|l|l|l|l|}
\hline Contact & \multicolumn{3}{|l|}{$\begin{array}{l}0.01 \\
\text { acid nitric }\end{array}$} & \multicolumn{2}{l|}{$\begin{array}{l}0.1 \underline{\mathrm{M}} \text { ammonium } \\
\text { citrate }\end{array}$} & \multicolumn{2}{l|}{0.1 M HEDPA } & \multicolumn{2}{l|}{0.1 M EDTA } \\
\hline & $\mathrm{Sr}$ & $\mathrm{Pb}$ & $\mathrm{Sr}$ & $\mathrm{Pb}$ & $\mathrm{Sr}$ & $\mathrm{Pb}$ & $\mathrm{Sr}$ & $\mathrm{Pb}$ \\
\hline 1 & 65.6 & 4.3 & 78.2 & 4.2 & 74.9 & 1.7 & 77.4 & 7.2 \\
\hline 2 & 18.8 & 11.6 & 20.8 & 39.4 & 21.9 & 29.2 & 20.8 & 84.3 \\
\hline 3 & 2.2 & 30.3 & 0.9 & 26.5 & 0.9 & 45.7 & 1.1 & 4.4 \\
\hline Total & 86.6 & 46.2 & 99.9 & 70.1 & 97.7 & 76.6 & 99.3 & 95.9 \\
\hline
\end{tabular}

The dependence of $\mathrm{Pb}$ extraction on the presence of the anions $\mathrm{NO}_{3}{ }^{-}$and $\mathrm{Cl}^{-}$has been studied in batch contact experiments. This experiment employed a solution of $0.01 \underline{\mathrm{M}}$ $\mathrm{Pb}\left(\mathrm{NO}_{3}\right)_{2}$ with varying concentrations of nitric acid and hydrochloric acid. The acids were varied in such a manner as to maintain a total anion concentration of $0.95 \mathrm{M}$. The aqueous solution was contacted in equal volume ratios with the SREX solvent and the aqueous phase sampled for analysis at equilibrium conditions. The results of this study are shown in Figure 16.

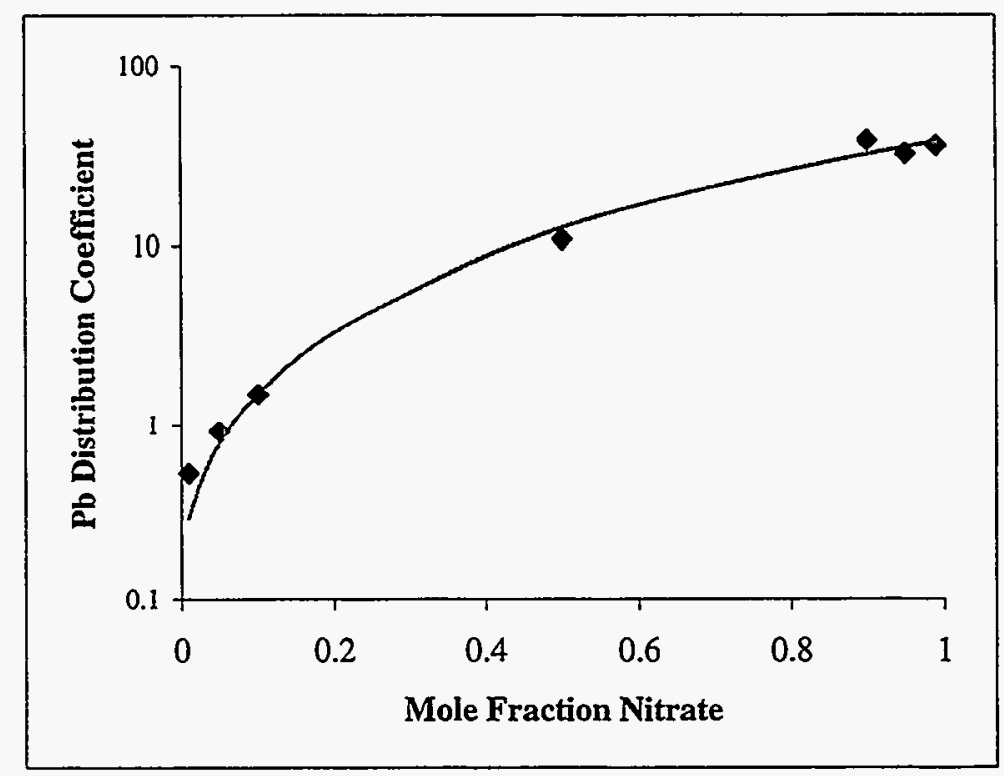

Figure 16. Dependence of $\mathrm{Pb}$ Extraction on Anion Molar Fraction. Aqueous phase: $0.01 \mathrm{M} \mathrm{Pb}\left(\mathrm{NO}_{3}\right)_{2}$ in a solution of nitric acid and hydrochloric acid with a total anion concentration of $0.95 \underline{\mathrm{M}}$. Organic phase: $0.15 \underline{\mathrm{M}} \mathrm{DtBuCH} 18 \mathrm{C} 6$ in 1.2 $\underline{\mathrm{M}} \mathrm{TBP} / \mathrm{Isopar} \mathrm{L}^{\circledR}$. 


\section{Extraction of $\mathrm{Hg}$ by the SREX Solvent}

The extraction of $\mathrm{Hg}$ by the SREX solvent has been investigated in batch contact experiments in order to evaluate the fate of $\mathrm{Hg}$ in processing flowsheets. The dependence of $\mathrm{Hg}$ extraction on nitric acid is shown and compared to that of $\mathrm{Sr}$ in Figure 16. The values for the $\mathrm{Hg}$ distribution coefficient are consistently much higher than that of $\mathrm{Sr}$. The extraction of $\mathrm{Hg}$ is quantitative at nitric acid concentrations above $0.7 \mathrm{M}$. This extraordinarily efficient extraction of $\mathrm{Hg}$ indicates an interferent in the SREX process when utilized for the partitioning of $\mathrm{Sr}$ from acidic wastes, containing $\mathrm{Hg}$.

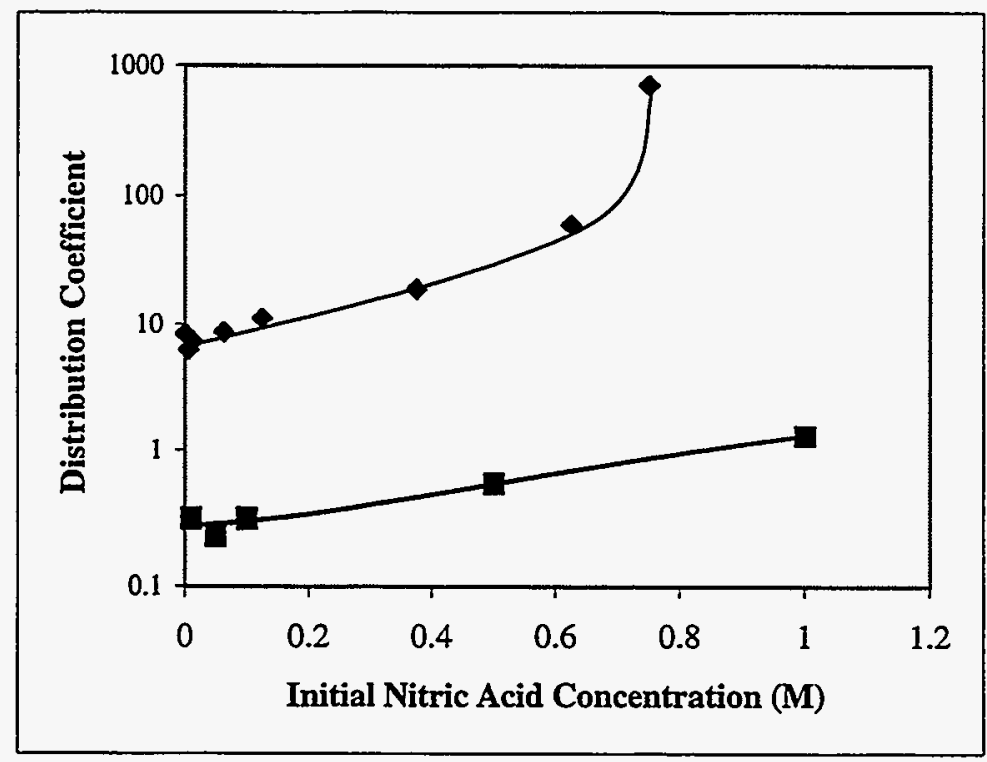

Figure 17. Dependence of $\mathrm{Hg}(\diamond)$ and $\mathrm{Sr}(\mathbf{I})$ Extraction on Nitric Acid with $0.15 \underline{\mathrm{M}}$ $\mathrm{DtBuCH} 18 \mathrm{C} 6$ in $1.5 \underline{\mathrm{M}} \mathrm{TBP} / \mathrm{Isopar} \mathrm{L}^{\circledR}$.

Laboratory studies of the extraction of $\mathrm{Hg}$ by the SREX solvent indicated that the removal (stripping) of $\mathrm{Hg}$ from the loaded SREX solvent is not easily accomplished. Various potential stripping reagents were evaluated for their ability to recover $\mathrm{Hg}$ from the loaded solvent. The ineffective reagents evaluated are listed in Table 13. Various concentrations of nitric acid were evaluated for the removal of $\mathrm{Hg}$ from the SREX solvent after contact with simulated sodium-bearing waste solutions.

The SREX solvent was contacted three times sequentially with fresh simulated sodium-bearing waste in organic:aqueous volumes ratios of $1: 1$. The solvent was then divided into three fractions and each of the fractions was contacted sequentially with nitric acid solutions of specific concentration. The results of this experiment are shown in Table 13. The removal of $\mathrm{Hg}$ from the SREX solvent is not highly efficient with nitric acid. 
Table 12. Reagents Determined to Be Ineffective for Stripping Hg from Loaded SREX Solvent.

\begin{tabular}{|l|l|l|}
\hline Reagent & Concentrations Evaluated & Observations \\
\hline Ammonium Citrate & $0.1 \underline{\mathrm{M}}$ & \\
\hline HEDPA & 0.01 & \\
\hline Thiourea & $0.1 \underline{\mathrm{M}}$ & Causes precipitate formation \\
\hline EDTA & $0.001,0.1 \underline{\mathrm{M}}$ & $0.1 \underline{\mathrm{M}}$ causes preciptate formation \\
\hline Ammonium Chloride & $0.05 \underline{\mathrm{M}}$ & \\
\hline Hydrofluoric Acid & $0.05 \underline{\mathrm{M}}$ & \\
\hline Sodium Carbonate & $0.05 \underline{\mathrm{M}}, 0.25 \underline{\mathrm{M}}$ & Causes precipitate formation. \\
\hline Hydrazine & $0.05 \underline{\mathrm{M}}$ & \\
\hline Hydrogen Peroxide & $0.05 \underline{\mathrm{M}}$ & \\
\hline Nitric Acid & $0.01,0.05,1,3,8,12 \underline{\mathrm{M}}$ & \\
\hline
\end{tabular}

Table 13. Distribution Coefficients of $\mathrm{Hg}$ with Various Nitric Acid Solutions.

\begin{tabular}{|l|l|l|l|l|}
\hline \multirow{3}{*}{ Contact } & Extraction Contacts & Strip Contacts & Strip Contacts & Strip Contacts \\
\cline { 2 - 5 } & Simulated SBW & $\begin{array}{l}3 \underline{\mathrm{M}} \text { nitric } \\
\text { acid }\end{array}$ & $\begin{array}{l}8 \underline{\mathrm{M}} \text { nitric } \\
\text { acid }\end{array}$ & $12 \underline{\mathrm{M}}$ nitric acid \\
\hline 1 & 34.2 & 6.2 & 2.4 & 1.8 \\
\hline 2 & 7.7 & 3.7 & 0.99 & 0.6 \\
\hline 3 & 8.9 & 3.1 & 0.8 & 0.8 \\
\hline 4 & & 3.0 & 0.64 & Not available \\
\hline
\end{tabular}

\section{Extraction of Na and $\mathrm{K}$ by the SREX Solvent}

Chemical derivatives of the macrocycle 18-crown-6 are known to exhibit high binding constants with the Group I cations and, in particular, potassium. The $\mathrm{K}^{+}$and $\mathrm{Na}^{+}$ ions are expected to present chemical interferences to the SREX process. For this reason, the extraction of $\mathrm{K}$ and $\mathrm{Na}$ has been studied in batch contact experiments. Previous work with the 1-octanol diluent (see Figure 8) has demonstrated the reduction of Sr extraction in the presence of the $\mathrm{Na}$ ion. Laboratory studies have indicated that the extraction of the $\mathrm{K}^{+}$ ion is dependent not only on the concentration of the nitrate ion, but also on the concentration of the $\mathrm{H}_{3} \mathrm{O}^{+}$ion. Extraction experiments have been performed in which the total nitrate concentration in the aqueous phase was held constant at $3.5 \mathrm{M}$. The concentration of the hydronium ion $\mathrm{H}_{3} \mathrm{O}^{+}$was varied from 0.01 to $3 \mathrm{M}$. These concentrations were obtained with $\mathrm{LiNO}_{3}$ and $\mathrm{HNO}_{3}$ stock reagents. The concentration of the metal cation of interest was $0.001 \mathrm{M}$. The extraction dependence of $\mathrm{K}$ and $\mathrm{Sr}$ are shown in Figure 18. The extraction of $\mathrm{K}$ is strongly dependent upon the concentration of $\mathrm{H}_{3} \mathrm{O}^{+}$, while the extraction of $\mathrm{Sr}$ exhibits only a slight dependence. Furthermore, the trends in the dependence of $\mathrm{K}$ are opposite that of Sr. This effect implies that it may be possible to selectively strip $\mathrm{K}$ from the loaded solvent, while retaining $\mathrm{Sr}$ in the organic phase. 
Similar experiments were performed with a solution of sodium nitrate in order to evaluate the dependence of the extraction of $\mathrm{Na}^{+}$on hydronium ion concentration.

However, the distribution of $\mathrm{Na}$ in the SREX solvent is very low, thus making the analytical results unreliable. The suppression of the Sr distribution coefficient by high concentrations of the $\mathrm{Na}$ ion, however, indicates that the $\mathrm{Na}$ ion does compete for extractant sites with the Sr ion in acid solutions (see discussion of Figure 8).

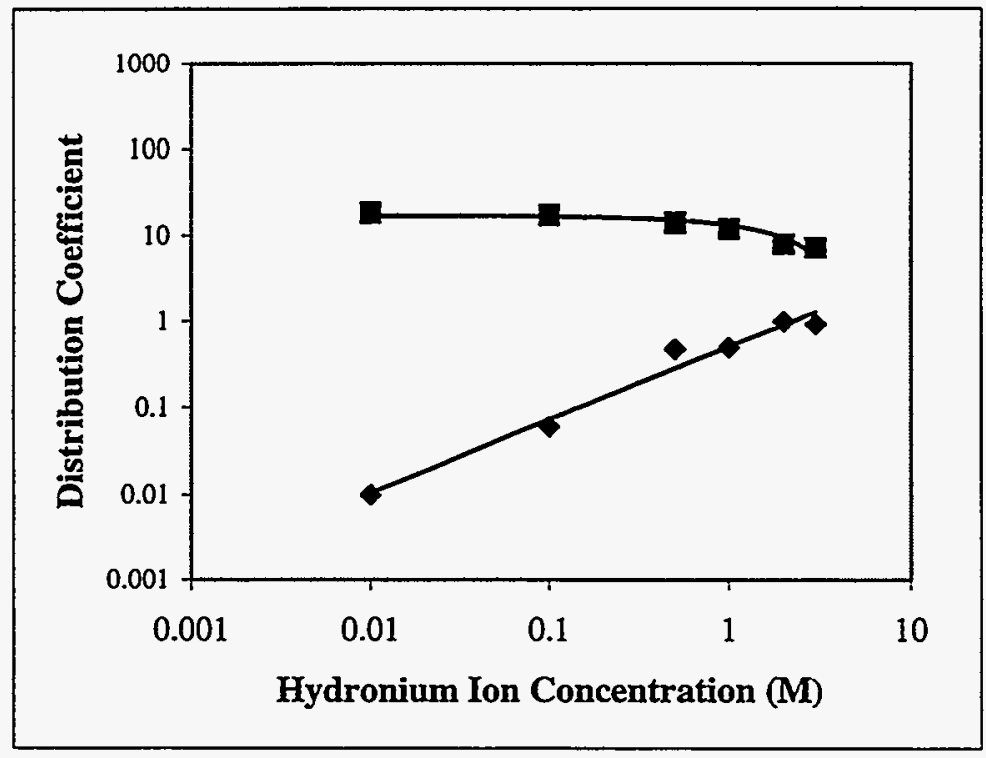

Figure 18. Dependence of $\mathrm{K}(\checkmark)$ and $\operatorname{Sr}(\mathbf{I})$ Extraction on hydronium ion concentration. Aqueous phase: $3.5 \underline{\mathrm{M}}$ nitrate ion with $0.001 \underline{\mathrm{M}} \mathrm{KNO}_{3}$ or $0.001 \underline{\mathrm{M} \mathrm{Sr}}\left(\mathrm{NO}_{3}\right)_{2}$, adjusted with $\mathrm{LiNO}_{3}$ and $\mathrm{HNO}_{3}$.

\section{Flowsheet Development for Sodium-Bearing Waste with TBP/ Isopar L $^{\circ}$ Solvent}

The evaluation of potential processing flowsheets for the treatment of sodiumbearing waste with the TBP/ Isopar $\mathrm{L}^{\circledR}$ solvent has been performed in batch contacts in crosscurrent experiments. The flowsheet was performed according to the diagram in Figure 19. The flowsheet was designed on the basis of the information gathered in the previous studies. The phase volume ratios (O:A) were selected based upon previous operating experience with countercurrent flowsheet design and predicted chemical behavior. The $2 \underline{M}$ nitric acid scrub was intended to reduce the mass of non-radioactive components such as $\mathrm{K}$ and $\mathrm{Na}$ which are co-extracted by the solvent. The $0.05 \mathrm{M}$ nitric acid strip was selected because the acid dependency plots of $\mathrm{Sr}$ and $\mathrm{Pb}$ indicate that this concentration will efficiently strip $\mathrm{Sr}$ from the loaded solvent, while maintaining a $\mathrm{Pb}$ distribution coefficient which is high enough to retain the extracted $\mathrm{Pb}$ fraction in the organic phase. The final contacts with $0.1 \underline{\mathrm{M}}$ ammonium citrate are intended to strip $\mathrm{Pb}$ because the solution is acid deficient, while forming soluble $\mathrm{Pb} /$ citrate solution complexes which eliminate precipitation in the countercurrent flowsheet. 


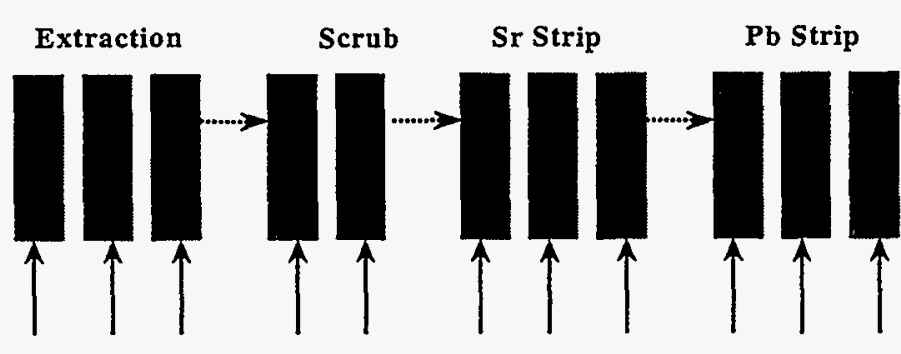

Simulated Waste $2 \mathrm{M}$ nitric acid $0.05 \mathrm{M}$ nitric acid $0.1 \mathrm{M}$ Ammonium Citrate
$\mathrm{O} / \mathrm{A}=\mathbf{1}$
$O / A=4$
$\mathrm{O} / \mathrm{A}=0.5$
$\mathrm{O} / \mathrm{A}=1$

Figure 19. Batch contact flowsheet for simulated SBW. Solid arrows: aqueous phase. Dashed arrows: organic phase. Organic phase: $0.15 \mathrm{MDtBuCH} 18 \mathrm{C} 6$ in 1.5 M TBP/Isopar $L^{\circledR}$. Aqueous phase: simulated WM-183 sodium-bearing waste spiked with radioisotopes in trace quantitites.

This batch contact flowsheet was evaluated in separate experiments to determine the chemical behavior of $\mathrm{Sr}, \mathrm{Pu}, \mathrm{U}, \mathrm{Am}$, and Tc. The actinides were evaluated because the tributylphosphate component of the solvent is expected to behave similarly to the PUREX process solvent and may extract these metals. Tc was evaluated because the fate of ${ }^{99} \mathrm{Tc}$ in the countercurrent process may be an important factor in the handling of final waste forms. The distribution coefficients for each of the components are shown in Table 14. The experiments indicate that $\mathrm{U}$ and $\mathrm{Pu}$ are efficiently extracted along with $\mathrm{Sr}$ in the extraction section of the flowsheet. Am and Tc both have measurable distributions which are much lower than the other components studied. While $\mathrm{Sr}$ is efficiently stripped in the first strip section ( $0.05 \mathrm{M}$ nitric acid), Tc is not stripped effectively by the strip procedures. $\mathrm{Pu}$ is likely to be stripped by the $0.05 \underline{\mathrm{M}}$ nitric acid strip procedure. The other actinides, $\mathrm{U}$ and $\mathrm{Am}$, are expected to be stripped under the same conditions, though this has not been evaluated experimentally. It should be noted that this flowsheet was conducted both with SREX solvent which had been contacted (washed) with $0.25 \underline{\mathrm{M}}$ sodium carbonate prior to experimentation and with fresh solvent which was prepared from reagents which had not been washed. The sodium carbonate procedure is known to remove degradation products from tributylphosphate in both the PUREX and TRUEX processes. It was observed that the distribution measurements for $\mathrm{Pu}$ and Am remained very high in the strip contacts when unwashed solvent was employed in the experiments. Washing the solvent with sodium carbonate allowed Pu to be efficiently stripped with dilute nitric acid. It is, therefore, 
important to remove TBP degradation products prior to the use of the SREX solvent when actinides are present in the aqueous feed solution. The solvent washing procedure is generally regarded as necessary before the solvent is used in any processing flowsheet.

Table 14. Distribution Coefficients for Selected Metals in Batch Contact Flowsheets with Simulated WM-183 Waste with the SREX Solvent Composed of 0.15 M DTBuCH18C6 in $1.5 \underline{\mathrm{M}} \mathrm{TBP} /$ Isopar $\mathrm{L}^{\circledR}$.

\begin{tabular}{|c|c|c|c|c|c|c|}
\hline Contact & Aqueous Phase & ${ }^{233} \mathrm{U}$ & ${ }^{239} \mathrm{Pu}$ & ${ }^{241} \mathrm{Am}$ & ${ }^{85} \mathrm{Sr}$ & ${ }^{99} \mathrm{Tc}$ \\
\hline Extract 1 & WM 183 Simulant & 32.9 & 79.6 & 0.20 & 6.25 & 1.45 \\
\hline Extract 2 & WM 183 Simulant & 50.1 & 114 & 0.22 & 6.04 & 1.42 \\
\hline Extract 3 & WM 183 Simulant & 59.5 & 125 & 0.23 & 5.35 & 1.41 \\
\hline Extract 4 & WM 183 Simulant & 67.4 & 160 & 0.25 & 5.25 & 1.37 \\
\hline Scrub 1 & $2 \mathrm{M}$ nitric acid & 31.9 & 31.9 & 0.26 & 4.36 & 1.75 \\
\hline Scrub 2 & $2 \overline{\mathrm{M}}$ nitric acid & 26.3 & 23 & 0.90 & 4.47 & 1.90 \\
\hline Strip 1 & $0.05 \mathrm{M}$ nitric acid & NA & 1.16 & $\mathrm{NA}$ & 0.39 & 5.07 \\
\hline Strip 2 & $0.05 \mathrm{M}$ nitric acid & NA & 0.12 & $\mathrm{NA}$ & 0.08 & 7.61 \\
\hline Strip 3 & $0.05 \mathrm{M}$ nitric acid & NA & $\mathrm{NA}$ & $\mathrm{NA}$ & $\mathrm{NA}$ & 9.36 \\
\hline Strip 4 & $0.05 \mathrm{M}$ nitric acid & $\mathrm{NA}$ & NA & $\mathrm{NA}$ & $\mathrm{NA}$ & 7.72 \\
\hline Strip 5 & $\begin{array}{l}0.1 \underline{\mathrm{M}} \text { ammonium } \\
\text { citrate }\end{array}$ & $\mathrm{NA}$ & $\overline{\mathrm{NA}}$ & $\mathrm{NA}$ & $\mathrm{NA}$ & 3.50 \\
\hline Strip 6 & $\begin{array}{l}0.1 \underline{\mathrm{M}} \text { ammonium } \\
\text { citrate }\end{array}$ & $\mathrm{NA}$ & NA & $\mathrm{NA}$ & NA & 3.25 \\
\hline Strip 7 & $\begin{array}{l}0.1 \underline{\mathrm{M}} \text { ammonium } \\
\text { citrate }\end{array}$ & $\mathrm{NA}$ & NA & $\mathrm{NA}$ & NA & 3.08 \\
\hline Strip 8 & $\begin{array}{l}0.1 \underline{\mathrm{M}} \text { ammonium } \\
\text { citrate }\end{array}$ & NA & NA & $\mathrm{NA}$ & $\mathrm{NA}$ & 3.00 \\
\hline
\end{tabular}

NA indicates that the measurement was below detection limits or not available.

The extraction of $\mathrm{Pu}, \mathrm{U}$, and Am is believed to be primarily affected by the presence of tributylphosphate in the SREX solvent. The presence of DtBuCH18C6 is not expected to play an important role in the extraction of the actinides. Experiments have been performed to determine the effect of the concentration of $\mathrm{DtBuCH} 18 \mathrm{C} 6$ in the organic phase. This dependence is shown in Figure 20. It can be seen from the plot that the extraction of $\mathrm{Pu}$, $\mathrm{Am}$, and $\mathrm{U}$ are not highly dependent on the concentration of the extractant. Sr and Tc show clear dependence on the concentration of $\mathrm{DtBuCH} 18 \mathrm{C} 6$. This may indicate that processing flowsheets may be designed with the assumption that the actinides will have similar chemical behaviors to that seen in the PUREX process, in which TBP is the intended and only extractant. Batch contacts have been performed to evaluate the dependence of the extractable species on equilibrium nitric acid concentration. Am, $\mathrm{U}, \mathrm{Pu}, \mathrm{Sr}$, and $\mathrm{Tc}$ have been shown to have significant dependence upon nitric acid as shown in Figure 21. 


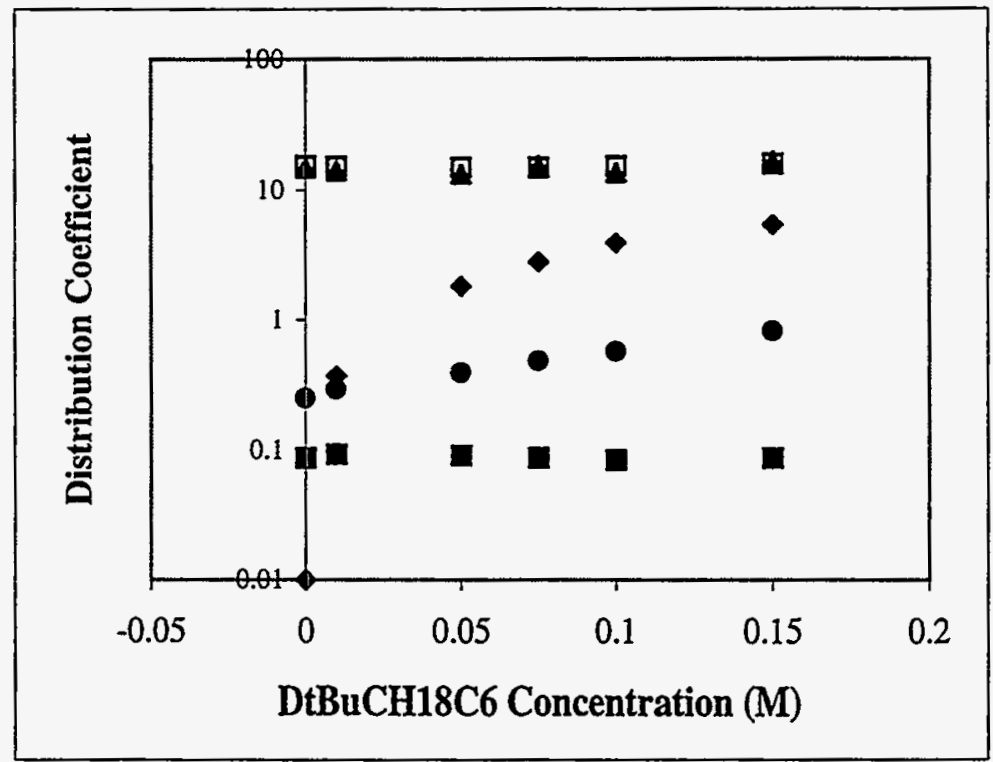

Figure 20. Dependence of extraction on concentration of extractant DtBuCH18C6 in 1.5 $\underline{\mathrm{M}} \mathrm{TBP} / \mathrm{Isopar} \mathrm{L}^{\circledR}$ for $\mathrm{Sr}(\bullet), \mathrm{Am}(\boldsymbol{\square}), \mathrm{Pu}(\mathbf{\Delta}), \mathrm{U}(\square)$, and Tc $(\bullet)$ in $3 \underline{\mathrm{M}}$ nitric acid.

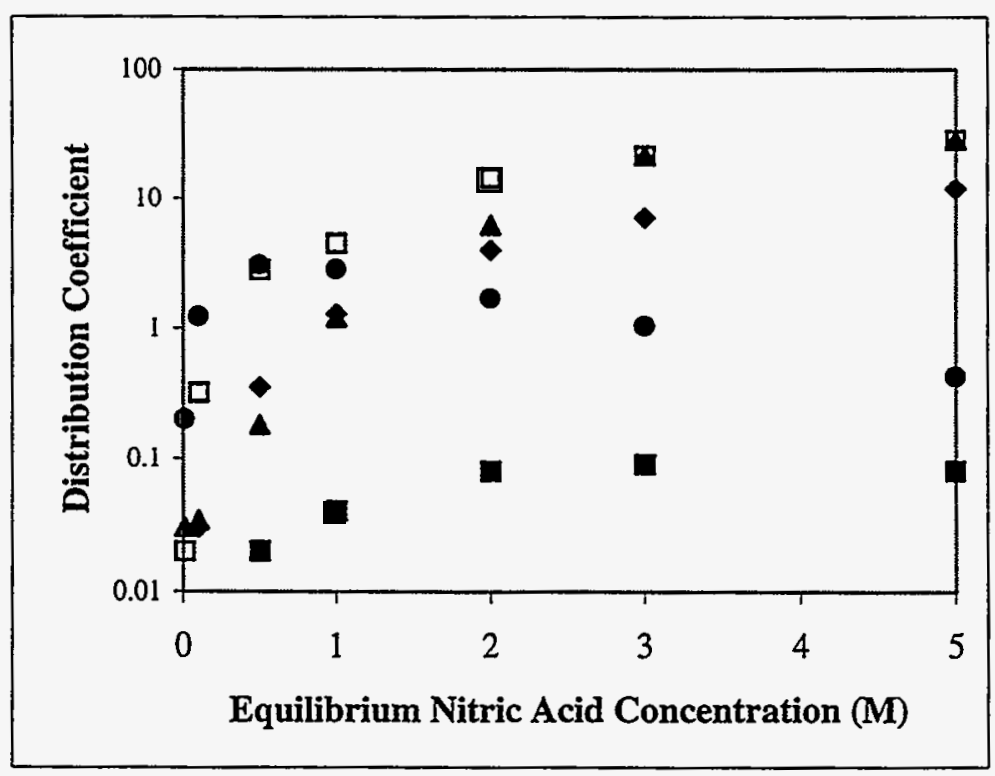

Figure 21. Dependence of extraction on concentration of nitric acid in the aqueous phase at equilibrium for $\operatorname{Sr}(\bullet), \operatorname{Am}(\mathbf{\square}), \operatorname{Pu}(\mathbf{\Lambda}), \mathrm{U}(\square)$, and $\mathrm{Tc}(\mathbf{O})$ in $3 \underline{\mathrm{M}}$ nitric acid with $0.15 \underline{\mathrm{M}} \mathrm{DtBuCH} 18 \mathrm{C} 6$ in $1.5 \underline{\mathrm{M}} \mathrm{TBP} / \mathrm{Isopar}^{\mathrm{Q}}$. 


\section{Radiolysis of the SREX Solvent}

Experiments have been performed to determine the effect of gamma radiation upon the extraction performance of the SREX Solvent. The effect of high radiation dose upon the solvent is important because the solvent is likely to be exposed to high radiation environments in processes which require extraction solvents which can be regenerated and recycled many times. Excessive degradation of the solvent requires the frequent and costly replacement of the solvent.

Radioactive calcined wastes at the ICPP have been reported to vary in dose at contact with a maximum of approximately $0.001 \mathrm{KGy} / \mathrm{Hr}(100 \mathrm{Rad} / \mathrm{Hr})$. It is expected that a solvent which was in contact with this maximum dose continuously would receive a total dose of $8.8 \mathrm{Kgy}$ in one year. The dependence upon the extraction of Sr by the solvent as a function of the dose from a gamma-emitting source is shown in Table 15. The table shows the results of batch contact experiments in which extractions were performed with the SREX solvent and $3 \underline{\mathrm{M}}$ nitric acid spiked with ${ }^{85} \mathrm{Sr}$ at with O/A equal to one. The extraction efficiency of the SREX solvent does not significantly change over the entire range studies, which is approximately equal to the dose that the solvent may receive in a period of ten years when used for the processing of ICPP wastes.

Table 15. Extraction of Sr as a Function of Total Received Gamma Dose.

\begin{tabular}{|l|l|l|l|l|l|}
\hline Sample & Dose (Kgy) & $\begin{array}{l}\text { Aqueous } \\
\text { Activity } \\
\text { (dps) }\end{array}$ & $\begin{array}{l}\text { Organic } \\
\text { Activity } \\
\text { (dps) }\end{array}$ & Sr Dist. Coeff. & Extraction \% \\
\hline Control & 0 & 34.9 & 268 & 7.67 & 0.88 \\
\hline 1 & 6.4 & 38.5 & 278 & 7.22 & 0.88 \\
\hline 2 & 24.2 & 35.2 & 214 & 6.1 & 0.86 \\
\hline 3 & 58.7 & 33.3 & 232 & 6.97 & 0.87 \\
\hline 4 & 86.8 & 40.7 & 263 & 6.46 & 0.87 \\
\hline 5 & 183 & 37.4 & 275 & 7.35 & 0.88 \\
\hline
\end{tabular}

The radiolytic degradation of the SREX solvent may also be of concern with regard to the stripping efficiency of the solvent. The effect of gamma radiation on the stripping behavior of Sr from the SREX solvent with $0.01 \mathrm{M}$ nitric acid has been studied in sequential batch contacts with SREX solvent which had been previously contacted with a solution of 3 $\mathrm{M}$ nitric acid spiked with ${ }^{85} \mathrm{Sr}$. Table 17 displays the measured distribution coefficients for ${ }^{85} \mathrm{Sr}$ for each of four sequential strip contacts for solvents which had received varying doses. The values for the distribution coefficients decrease slightly with increasing absorbed dose. In general, the data indicate that the removal of $\mathrm{Sr}$ from the loaded organic phase becomes more efficient with higher absorbed doses. 
Table 16. Distribution Coefficient for ${ }^{85} \mathrm{Sr}$ in Stripping Procedure with Irradiated Solvent at Varying Absorbed Doses.

\begin{tabular}{|l|l|l|l|l|l|l|}
\hline $\begin{array}{l}\text { Contacts with } \\
0.01 \text { M nitric } \\
\text { acid }\end{array}$ & $0 \mathrm{KGy}$ & $8.6 \mathrm{KGy}$ & $110 \mathrm{KGy}$ & $206 \mathrm{KGy}$ & $496 \mathrm{KGy}$ & $\begin{array}{l}1040 \\
\text { KGy }\end{array}$ \\
\hline 1 & 1.3 & 1.12 & 1.04 & 1.01 & 0.79 & 0.6 \\
\hline 2 & 0.25 & 0.20 & 0.16 & 0.179 & 0.13 & 0.112 \\
\hline 3 & 0.06 & 0.06 & 0.05 & 0.048 & 0.05 & 0.03 \\
\hline 4 & 0.03 & 0.03 & NA & NA & NA & NA \\
\hline
\end{tabular}

NA indicates that the measurement was below detection limits or not available.

The combined effect of radiolysis and hydrolysis may increase the chemical degradation of the SREX solvent. Experiments have been performed to evaluate the effect of nitric acid concentration on the extraction of Sr by the SREX solvent which has been subjected to high doses of gamma radiation. The SREX solvent was first contacted with solutions of varying nitric acid concentration. The organic phase was subsequently removed from contact with the aqueous phase and subjected to a total dose of 1000 KGy. The solutions were then contacted with a solution of $3 \underline{M}$ nitric acid spiked with ${ }^{85} \mathrm{Sr}$. The measured distribution coefficients are shown in Table 17. The data indicate that prior contact of the SREX solvent with nitric acid does not significantly alter its extraction characteristics.

Table 17. Extraction of Sr as a Function of Nitric Acid with Irradiated SREX Solvent.

\begin{tabular}{|l|l|l|}
\hline $\begin{array}{l}\text { Pre-equilibrated } \\
\text { Nitric Acid (M) }\end{array}$ & $\begin{array}{l}\text { Sr Dist. Coeff. } \\
\text { Simulated SBW }\end{array}$ & $\begin{array}{l}\text { Sr Dist. Coeff. } \\
3 \text { M nitric Acid }\end{array}$ \\
\hline 0.01 & 2.37 & 4.44 \\
\hline 0.05 & 2.23 & 4.36 \\
\hline 0.1 & 2.44 & 4.45 \\
\hline 0.5 & 2.32 & 4.50 \\
\hline 1 & 2.18 & 4.97 \\
\hline 3 & 2.24 & 4.63 \\
\hline 5 & 2.07 & 4.37 \\
\hline
\end{tabular}




\section{CONCLUSIONS}

The evaluation of the SREX Process as a solvent extraction process for the remediation of acidic radioactive liquids at the ICPP has been performed. The laboratory testing (detailed in this report) and counter-current testing (detailed in other reports) indicate that this process is a highly effective method for the removal of ${ }^{90} \mathrm{Sr}$ from tank waste and dissolved calcine wastes at the ICPP.

The decontamination of simulated and actual wastes with respect to ${ }^{90} \mathrm{Sr}$ has been achieved in batch contacts. The decontamination factors obtained in these experiments are suitable high to indicate that the SREX process may be implemented for the treatment of high activity wastes to produce NRC class A low-level wastes.

The use of mixtures of tributyl phosphate and Isopar $L^{\circledR}$ as the diluent for the process solvent has been identified as having physical characteristics which are more desirable than the 1-octanol diluent which was studied in the early phases of this work. It should be noted, however, that the barriers to implementation of a solvent based upon 1-octanol are largely present because of perceived safety hazards and are not viewed as technical problems.

The extractant, $\mathrm{DtBuCH} 18 \mathrm{C} 6$, which is commercially manufactured in the United States in multi-kilogram quantities per year, is an effective reagent for the extraction of $\mathrm{Sr}$ from the waste streams. The chemical synthesis of this compound is important to its efficiency and wide variation in performance has been observed among manufacturers. This emphasizes the necessity to identify requirements for its performance when large quantities are procured for process-scale operation.

$\mathrm{DtBuCH} 18 \mathrm{C} 6$ has been shown to be highly selective for $\mathrm{Sr}$ in the presence of many metal ions. The major metals which are extractable by this extractant have been identified as $\mathrm{Sr}, \mathrm{Pb}, \mathrm{Hg}, \mathrm{Pu}, \mathrm{U}, \mathrm{Tc}$ (as $\mathrm{TcO}_{4}{ }^{-}$), $\mathrm{K}$, and $\mathrm{Ba}$. $\mathrm{Ba}$ is not a major component in ICPP wastes and is unlikely to present obstacles in the working flowsheet. The presence of the other extractables, however, may interfere with the decontamination of the waste stream and may have impacts upon final waste form considerations. The presence of these metals in the aqueous feed to the SREX process need to be carefully addressed in the design of process flowsheets. The stripping of $\mathrm{Hg}$ from the loaded solvent has not been fully evaluated. The difficulty of removing the $\mathrm{Hg}$ from the SREX solvent must be considered in further development activities.

The radiolysis of the SREX solvent is being studied. Initial results indicate that the radiolytic degradation of the solvent from very low doses of gamma radiation to $1000 \mathrm{KGy}$ have very little effect on its extraction and stripping performance. The distribution coefficients for $\mathrm{Sr}$ remain unchanged as a function of absorbed dose in solutions of nitric acid and in simulated waste solutions. 


\section{REFERENCES}

1. A. L Olson, W. W. Schulz, L. A. Burchfield, C. D. Carlson, J. L. Swanson, and M.

C. Thompson, Evaluation and Selection of Aqueous Based Technology for

Partitioning Radionuclides from ICPP Calcine, WINCO-1071, February 1993.

2. E P. Horwitz, M. L. Dietz, and D. E. Fisher, "Extraction of Strontium from Nitric Acid Solutions Using Dicyclohexano-18-Crown-6 and its Derivatives," Sol. Extr. \& Ion Exch., $\underline{8}(4 \& 5), 557-572,1990$.

3. E. P. Horwitz, M. L. Dietz, and D. E. Fisher, "SREX: A New Process for the Extraction and Recovery of Strontium from Acidic Nuclear Waste Streams," Sol. Extr. \& Ion Exch., 9 (1), 1-25, 1991.

4. V.V. Yakshin, B.F. Myasoedov, O.M. Vilkova, A.M. Tuzova, A.T. Fedorova, and I.M. Rodionova, Radiokhimiya 31, 67,1989.

5. E. P. Horwitz, M. L. Dietz, and D. E. Fisher, "Extraction of Strontium from Acidic Nitrate Media using a Modified PUREX Solvent," Sol. Extr. \& Ion Exch., 13(1), 117, 1995.

6. D.J. Wood, T.J. Tranter, and T.A. Todd, "Effect of the Interference of Alkali and Alkaline Earth Metal Ions on the Extraction of ${ }^{90} \mathrm{Sr}$ from Acidic Nuclear Waste Solutions by 18-crown-6 Derivatives" Solv. Extr. and Ion Exch., 13 (5), 829844,1995.

7. D. J. Wood, J.D. Law, and P.A. Tullock, "Extraction of Lead and Strontium from Hazardous Waste Streams by Solvent Extraction with 4', 4' (5')-di-(t-butyldicyclohexano)-18-crown-6," Solv. Extr. and Ion Exch., 15 (1), 65-78, 1997.

8. D. J. Wood and J. D. Law, "Evaluation of the SREX Solvent Extraction Process for the Removal of ${ }^{90} \mathrm{Sr}$ and Hazardous Metals from Acidic Nuclear Waste Solutions Containing High Concentrations of Interfering Alkali Metal Ions," Sep. Sci. \& Tech., 32(1-4), 241-253, 1997.

9. J. D. Law, D. J. Wood, and R. S. Herbst, SREX Flowsheet Development for the Separation of Strontium from ICPP Sodium-Bearing Waste Using Centrifugal Contactors, INEL-95/0314, September 1995. 